\title{
Spectroscopy Transmittance by LED Calibration
}

\author{
Daniel Carreres-Prieto ${ }^{1, * \mathbb{D}}$, Juan T. García ${ }^{1, * \mathbb{D}}$, Fernando Cerdán-Cartagena ${ }^{2}$ and \\ Juan Suardiaz-Muro ${ }^{3}$ iD \\ 1 Department of Mining and Civil Engineering, Technical University of Cartagena, 30202 Cartagena, Spain \\ 2 Department of Information and Communications Technologies, Technical University of Cartagena, \\ 30202 Cartagena, Spain \\ 3 Department of Electronic Technology, Technical University of Cartagena, 30202 Cartagena, Spain \\ * Correspondence: daniel.carreres@upct.es (D.C.-P.); juan.gbermejo@upct.es (J.T.G.)
}

Received: 30 May 2019; Accepted: 2 July 2019; Published: 4 July 2019

\begin{abstract}
Local administrations demand real-time and continuous pollution monitoring in sewer networks. Spectroscopy is a non-destructive technique that can be used to continuously monitor quality in sewers. Covering a wide range of wavelengths can be useful for improving pollution characterization in wastewater. Cost-effective and in-sewer spectrophotometers would contribute to accomplishing discharge requirements. Nevertheless, most available spectrometers are based on incandescent lamps, which makes it unfeasible to place them in a sewerage network for real-time monitoring. This research work shows an innovative calibration procedure that allows (Light-Emitting Diode) LED technology to be used as a replacement for traditional incandescent lamps in the development of spectrophotometry equipment. This involves firstly obtaining transmittance values similar to those provided by incandescent lamps, without using any optical components. Secondly, this calibration process enables an increase in the range of wavelengths available (working range) through a better use of the LED's spectral width, resulting in a significant reduction in the number of LEDs required. Thirdly, this method allows important reductions in costs, dimensions and consumptions to be achieved, making its implementation in a wide variety of environments possible.
\end{abstract}

Keywords: LED spectrophotometer; LEDs; water pollutants

\section{Introduction}

Continuous and on-line quality monitoring of wastewater and stormwater is nowadays a primal objective to comply with the Urban Wastewater Treatment Directive (UWWTD 91/271/EEC), Bathing Water Directive (BWD, 2006/7/EC) and the Environmental Quality Standards Directive (EQS, 2008/105/EC). Variable wavelength spectroscopy is a non-destructive technique without the addition of chemicals reagents to wastewater that can be used for the quality monitoring and real-time control of sewers [1,2].

Several authors have proposed partial least squares calibration models for the indirect monitoring of chemical oxygen demand (COD) or total suspended solids (TSS) through Ultraviolet-Visible (UV-VIS) and Visible (VIS) spectroscopy for wastewater and stormwater combined sewer overflows (CSOs) [3-5]. Continuous and consistent data collection in sewers are presented. Spectrometer calibration experiments for total-COD in Reference [6] resulted in an absolute error in the range of 30-300 $\mathrm{mg} \mathrm{COD} / \mathrm{L}$ and a corresponding relative error in the range of $8-60 \%$, where validation experiences led to underestimating high concentrations during daily peaks and in overestimating low concentrations during night periods [6,7].

Dissolved organic matter (DOM) was described by ratios of UV absorbance at $254 \mathrm{~nm}$ and $365 \mathrm{~nm}$ [8]. Different researchers have studied the absorbance at different wavelengths and its 
relation between different wavelength-absorbance as an indicator of the COD [8-10]. UV-Vis and VIS spectroscopy was performed in the wavelength range of $200-400 \mathrm{~nm}$, where it was found that the ratio of absorbance at 250 and $365 \mathrm{~nm}$ was a good measurement for the COD correlation [10]. Ultraviolet-visible absorption spectra in two distinct spectral slope regions (275-295 nm and 350-400 nm) within log-transformed absorption spectra were used to compare DOM concentrations from contrasting water types [11].

Pollutants track-down during CSOs through cost-effective methods is demanded by municipalities to comply with legal requirements $[12,13]$. In the same way, industrial wastewater discharge control throughout the sewer systems is of great interest for administrations nowadays. Therefore, a large number of sensors are required for the real-time control of the CSOs and industrial discharges in the sewer systems during rainfall events and dry periods. To achieve this real-time monitoring of pollution in sewers, a robust, portable and cost-effective device is needed to continuously monitor quality in sewers.

LED lights have been selected as a replacement for traditional incandescent lamps, due to their low consumption, cost and the fact that they reach their operating regime almost immediately, which reduces downtime. The specific objective of this research is the development of a precision spectrophotometer, based on LED technology, and which is cost-effective, portable and with consumptions much lower than those provided by incandescent lamps [14], to enable them to be located in sewers systems massively. For the validation and acceptance of results obtained with LEDs, the first steps of the present work were dedicated to reproducing and comparing them to commercial equipment. The advantage of reproducing the footprint of a commercial spectrometer is the validation of the transmittance values with LED technology according to the configuration proposed in the present work, which avoids the use of an optical lens covering a wide range of wavelengths.

Therefore, the present research includes a calibration process that can be useful for the design of an innovative LED spectrophotometer capable of operating at a wide range of wavelengths. This availability of a greater working range (far beyond that of a turbidimeter that operates under a single wavelength, typically $860 \mathrm{~nm}$ ) is expected to enable a more exhaustive analysis of a sample's properties. Depending on the composition and concentration of wastewater and stormwater, variations in transmittance and absorbance values will be detected in certain regions of the working spectrum, which could enable a greater number of indirectly contaminating parameters to be determined.

Different types of LED based on light sources could be used in a spectrophotometer [15], but in practice not all are adequate for this purpose. In general, we can divide the types of LEDs into three categories: White light LED, RGB LED, and limited-bandwidth LED (Common LED).

In spectrophotometry, the use of white light for generating the working spectrum is a common practice. White light requires the use of optical elements, such as monochromators [16]. This supposes an increase in the cost of the equipment and in its dimensions, while making them more sensitive to mismatch as a result of impacts or vibrations, and thus not being suitable for all types of environments. There are studies [17] that raise the feasibility of using LED technology for the generation of white light, however, it must be pointed out that this type of LED semiconductor has a different emission spectrum than monochromatic white light. These are based on blue LEDs that are coated with a layer of phosphorus, which react with short wavelengths (blue), emitting low energy yellow light. Therefore, this type of LED is currently not the best solution for the generation of white light for spectrophotometry operations.

RGB LEDs were used to generate different wavelengths in the visible spectrum and through the combination of the three primary colors (Red, Green and Blue) with different levels of emission intensity [18]. An RGB LED is composed of three individual LEDs, that is, a red, green and blue LED that emit at specific wavelengths. However, in order to clarify the explanations, we shall refer to this type of light source as "RGB LED", as these three LEDs are inside the same housing.

The idea of generating all the wavelengths that make up the visible spectrum using an RGB LED was shown to be unfeasible. It is based on an incorrect understanding of the human eye to affirm 
that certain wavelengths are being emitted [19], when in fact the primary colors are being emitted separately at different intensity levels, giving rise to an optical effect known as "rendering of color" [20]; television monitors are based on this. Although empirical equations exist between the values of $\lambda$ and RGB, such as the Fortran code [21,22], which is one of the most used color generation systems in LED screens, this "color matching" cannot be used for the development of spectrophotometric equipment by only emitting the wavelengths corresponding to red: $625 \mathrm{~nm}$; green: $525 \mathrm{~nm}$; and blue: $460 \mathrm{~nm}$ [19].

Common LEDs represent the best option for the development of portable and cost-effective equipment. LED diodes are designed to emit in a limited range of wavelengths simultaneously (spectral width), so they are suitable for describing specific regions of the visible spectrum. Herein, in the present work we will refer to this type of LED.

The contributions of this work as follows: First, an innovative calibration process of the transmittance values for these LEDs without the use of optical elements such as lenses and diffraction matrix; thus reducing costs, dimensions and complexity. Second, increasing the valid range of wavelengths of each LED, in addition to its own peak wavelength. This allows the number of LEDs to be significantly reduced.

The rest of the article is organized as follows:

In Section 2, all the materials and methods used in this research work are explained. The section details the samples analyzed, the type of sensor used, as well as the commercial equipment based on incandescent lamps used as a reference during the calibration process. Likewise, the assembly carried out during the experiment is described, in order to provide a detailed guide to reproduce the results.

Section 3 focuses on the study of the use of LEDs as a viable alternative to incandescent lamps, detailing the limitations and problems associated with them. The need for a specific calibration process is evident to match the results obtained with reference commercial equipment based on incandescent lamps. The results obtained after the calibration process are also presented.

Finally, Section 4 discusses the considerations reached at the end of the research work.

\section{Materials and Methods}

\subsection{Analyzed Samples}

In order to enable different values of transmittance to be compared, 21 different samples were prepared of different natures and concentrations, as shown in Figure 1. Moreover, Table 1 describes the different substances employed in each sample and their dissolution.

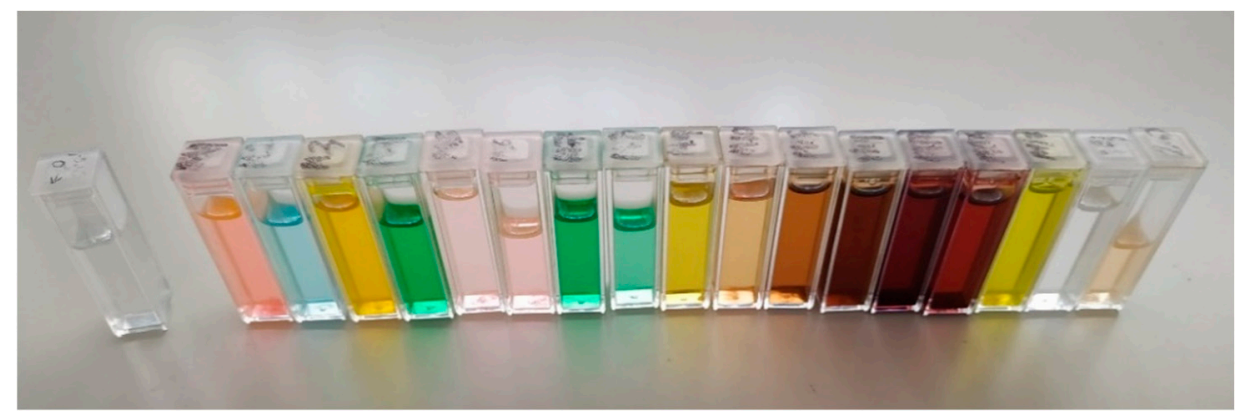

Figure 1. View of the 21 samples used in the present analysis.

It should be noted that samples M11 and M12 were discarded from the present study due to the fact that all the incident light was absorbed, making the transmittance value null.

All these samples were stored in standard $12 \times 12 \times 50 \mathrm{~mm}$ plastic test tubes specially designed for spectrophotometry. 
Table 1. Analyzed samples.

\begin{tabular}{ccc}
\hline Designation & Substance & Dissolution \\
\hline M0 & Distilled water & $100 \%$ \\
M1 & Red food coloring 40 & $50 \%$ \\
M2 & Blue food coloring & $50 \%$ \\
M3 & Yellow food coloring & $40 \%$ \\
M4 & Washing machine detergent & $50 \%$ \\
M5 & Red food coloring 40 & $75 \%$ \\
M6 & Red food coloring 40 & $55 \%$ \\
M7 & Washing machine detergent & $65 \%$ \\
M8 & Washing machine detergent & $75 \%$ \\
M9 & Kitchen oil & $100 \%$ \\
M10 & Vinegar & $90 \%$ \\
M11 & Milk & $100 \%$ \\
M12 & Milk & $50 \%$ \\
M13 & Soluble coffee & $75 \%$ \\
M14 & Soluble coffee & $50 \%$ \\
M15 & Red wine & $100 \%$ \\
M16 & Red wine & $50 \%$ \\
M17 & Blue and Yellow food coloring & $20-80 \%$ \\
M18 & Blue food coloring & $30 \%$ \\
M19 & Sea water & $100 \%$ \\
M20 & Tea & $80 \%$ \\
M21 & Fabric softener & $40 \%$ \\
\hline
\end{tabular}

\subsection{Sensors}

Individual photodiodes were used in the present work rather than Charge-Coupled Device (CCD) sensors [23]. The individual photodiode is designed to capture a single beam of incident light [24,25]. These are sensitive to a wide range of wavelengths. This enables the dimensions and costs of the equipment to be reduced [26]. A single sensor usually collects a larger area in proportion to that of the photodiodes of the CCD.

The individual photodiodes have a different spectral response depending on the incident wavelength. This is the sensor sensitivity. To study the effect of sensitivity in the measurements of transmittance, values at different wavelengths and two types of photodiodes with different sensitivities have been used to determine the most appropriate. These are S1223-01 [27] and OSD15-E [28], the spectral responses of which are shown in Figure 2.

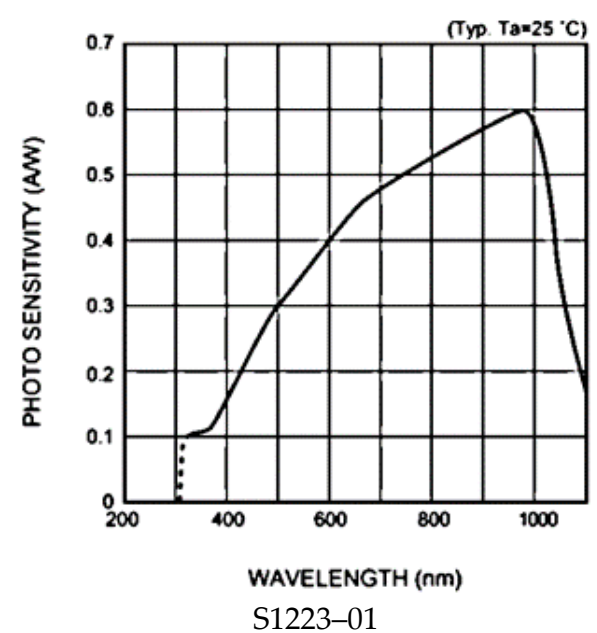

(A)

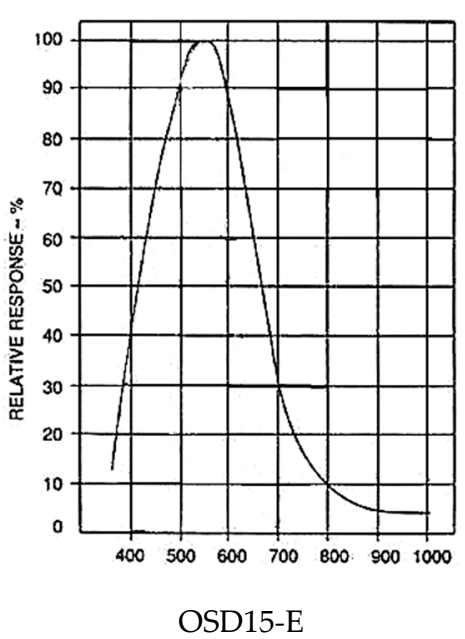

(B)

Figure 2. Sensitivity curves of the photodiodes (A) S1223-01 and (B) OSD15-E. 


\subsection{Light Emitting Diode (LED)}

As the source of light, traditional incandescent lamps were replaced by LEDs of $5 \mathrm{~mm}$ in diameter, which emit a fixed range of wavelengths determined by their manufacturing process. These are low energy consumers, cost-effective and are commercially available in a wide variety of peak wavelengths. This type of LED is designed to emit a narrow range of wavelengths simultaneously [29] and according to a normal distribution curve shape (Figure 3). The spectral width of an LED is defined by those wavelengths that have an emission intensity equal to or greater than $50 \%$, as shown in Figure 3.

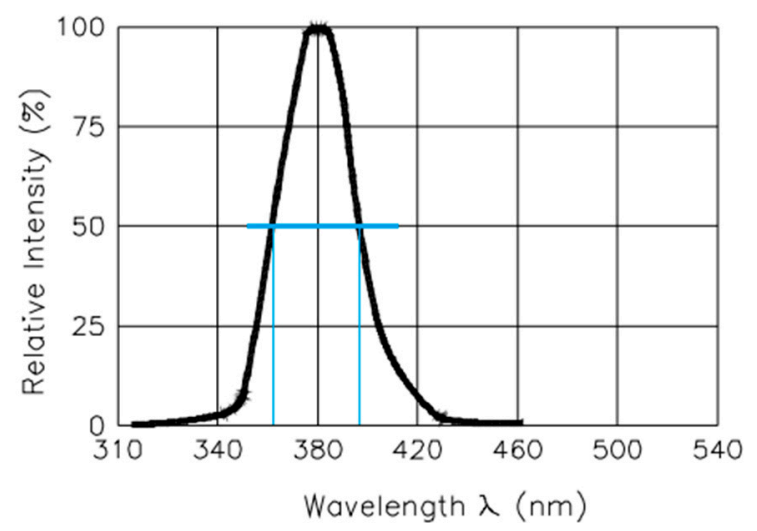

Figure 3. Emission spectrum of 385 nm LED (VAOL-5EUV8T4) [30].

For instance, the VAOL-5EUV8T4 LED shown in Figure 3 [30], emits at $385 \mathrm{~nm}$ at its maximum intensity level (peak wavelength) and at $400 \mathrm{~nm}$ at the upper limit of the spectral width of the LED, also known as "center wavelength", $\lambda_{0.5 \mathrm{~m}}$, which is defined as the wavelength halfway between the two points with a spectral density of $50 \%$ of the peak.

The whole range of wavelengths are emitted simultaneously. This results in higher values of transmittance than those provided by a spectrophotometer based on incandescent lamps. As shown in Figure 4 in the case of the $385 \mathrm{~nm}$ wavelength, the results provided by the LED reach deviations in the range of $14-20 \%$ with respect to the values obtained by means of the commercial equipment. Therefore, a calibration process to compensate for this deviation is required. Brightness selection will also be discussed in the present work.

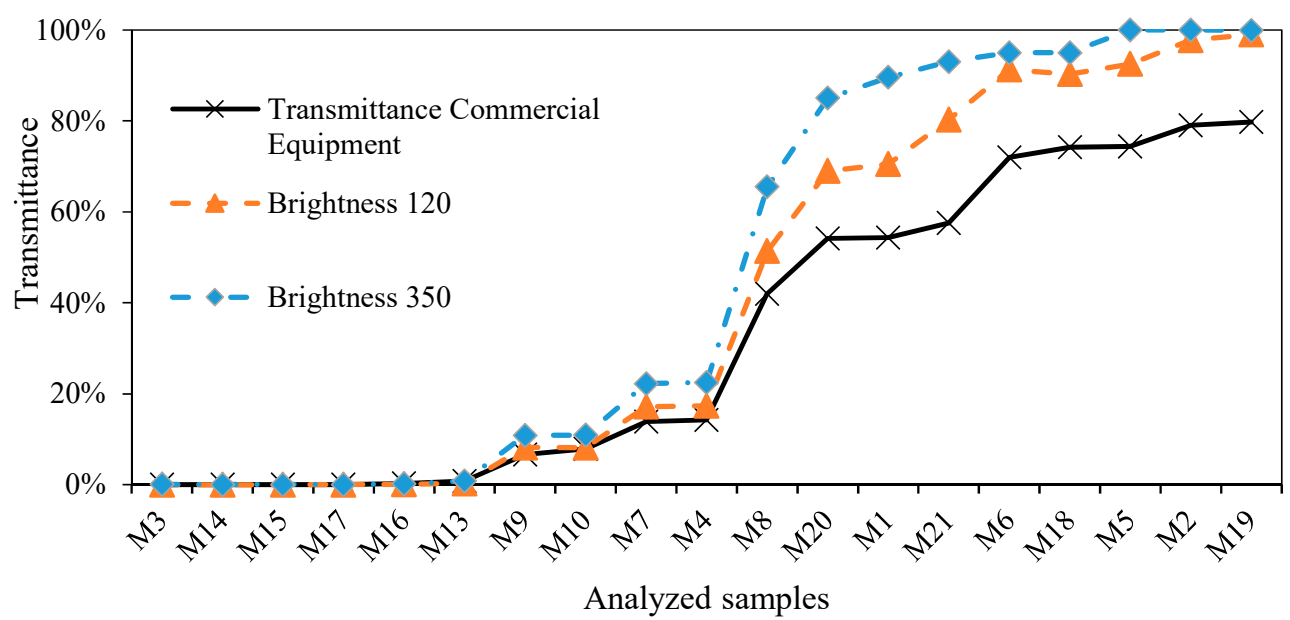

Figure 4. Transmittance comparison at $385 \mathrm{~nm}$ between commercial equipment and LED VAOL-5EUV8T4 [30] with two different brightnesses. 
To characterize the transmittance between 380 and $700 \mathrm{~nm}$ in a first attempt 59 LEDs were needed. At the end of this research work, through the optimization of the wavelength calibration and selection process we had reduced this number to 34 LEDs. These 34 LEDs are listed in the Appendix A (Table A1).

\subsection{Hardware}

In order to reduce the dimensions of the equipment and thus improve its portability, in the present research work it was decided to eliminate the use of any optical elements such as lenses, diffraction matrix or monochromators.

The proposed assembly is shown in Figure 5, constructed entirely in black thermoplastic Polylactic Acid (PLA) by a 3D printer. The tests carried out revealed that the most accurate results were obtained when the sensor (Figure 5 right) was as close as possible to the sample without touching it, and the light source (Figure 5 left) was at a distance of about $20 \mathrm{~mm}$ with reference to the test tube.

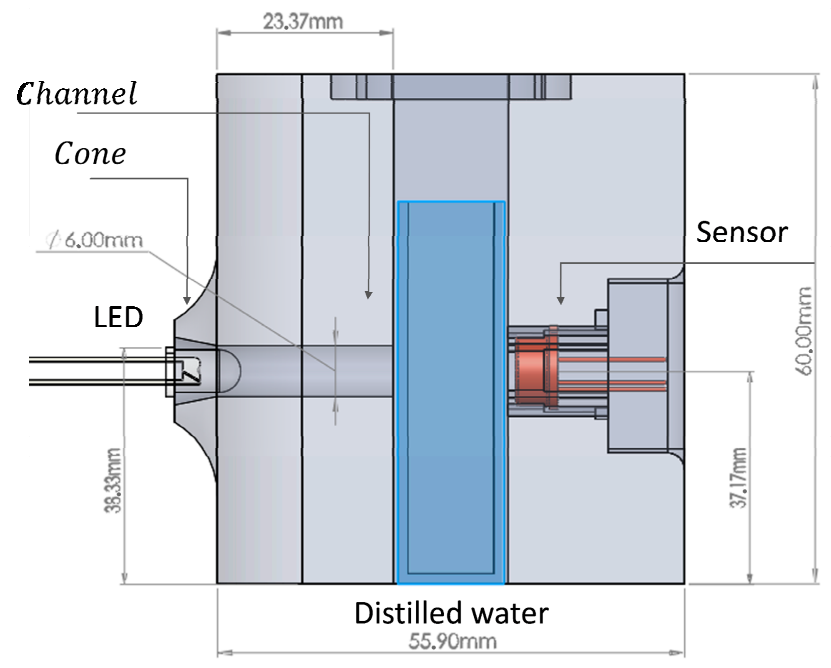

Figure 5. View of experiment assembly.

To minimize the dispersion of the LED light beam, it was necessary to have a cone-shaped entrance area to capture a greater amount of light, as can be seen in Figure 5. Additionally, a channel directing the beam to the center of the sample was needed. This channel needed to have a diameter slightly greater than the diameter of the LED so as not to obstruct the passage of light.

\subsection{Reference Equipment}

In the present work, all the results have been contrasted with the commercial equipment V-5000 VIS [31]. This has a working spectrum between 325 and $1000 \mathrm{~nm}$, with a bandwidth of $4 \mathrm{~nm}$, which complies with the following standards:

- ISO 22891: 2013: Determination of transmittance by diffuse reflectance measurement.

- ISO 10110-9: 2016: Preparation of drawings for optical elements and systems-Part 9: Surface treatment and coating.

- ISO 7887:2011: Water Quality-Examination and determination of color.

- ISO 9001 7.6 Control of monitoring and measuring equipment.

\subsection{Brightness Level Definition}

The definition of the brightness level of the LEDs is a key aspect of the entire calibration process. Higher values will cause sensor saturation, while low values may not allow the light to pass through the sample. To enable the brightness level to be varied, a driver [32] with a resolution of 16 bits has been used, capable of providing a maximum of $40 \mathrm{~mA}$ to each LED. The use of 16 bits provides 
a range of brightness levels between 0 and 4095 [33,34], the value at which the maximum level of illumination is reached ( $40 \mathrm{~mA})$. Based on this, a brightness level of 100 corresponds to a current of $0.977 \mathrm{~mA}$. Continuing with this example, the level of brightness 100 has been designated with the nomenclature T B100, used throughout this article. Low brightness levels are typically used when using high luminescence LEDs located a short distance from the sensor.

In this way, we consider that the amount of light detected (with a test tube of distilled water) corresponds to that emitted by the LED, ignoring the possible losses produced by the dispersion of the beam at the entrance of the channel (LED viewing angle).

\subsection{Methodology}

To carry out the calibration process that allows LED technology to produce results comparable to those obtained with incandescent lamps, it is necessary to carry out an adequate data collection. To do this, the transmittance values obtained by using LEDs of different peak wavelengths on different samples must be recorded (Table 1), so that they can be contrasted with the transmittance values obtained by means of the commercial equipment [31].

The methodology and procedure followed (with the help of software and electronic components) to obtain the data used for the measurement and calibration process are shown in Figure 6. This figure also shows the duration of the transmittance tests.

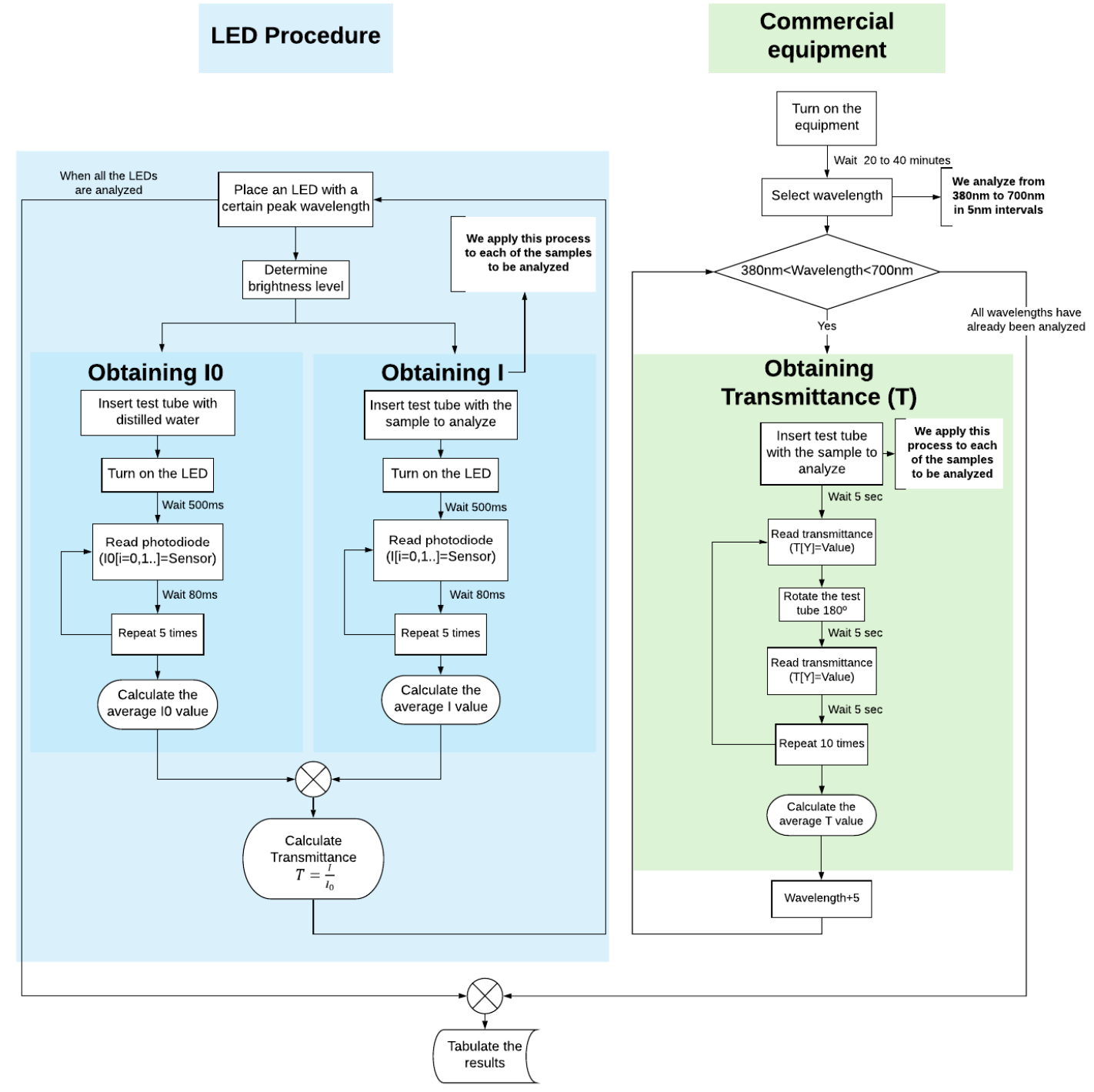

Figure 6. Scheme of the work methodology. 


\section{Result and Discussion}

\subsection{Preliminary Tests}

As seen in Figure 7, when performing an analysis through 59 LEDs with $\lambda_{\text {peak }}$ between 385 and $700 \mathrm{~nm}$, discrepancies in the transmittance values in comparison with the reference equipment based on incandescent lamps are observed. In this figure, each of the LEDs used has been denoted by a vertical line. Each LED operates at a wide range of wavelengths when it is traversing the sample (Figure 3), resulting in higher than expected transmittance values.

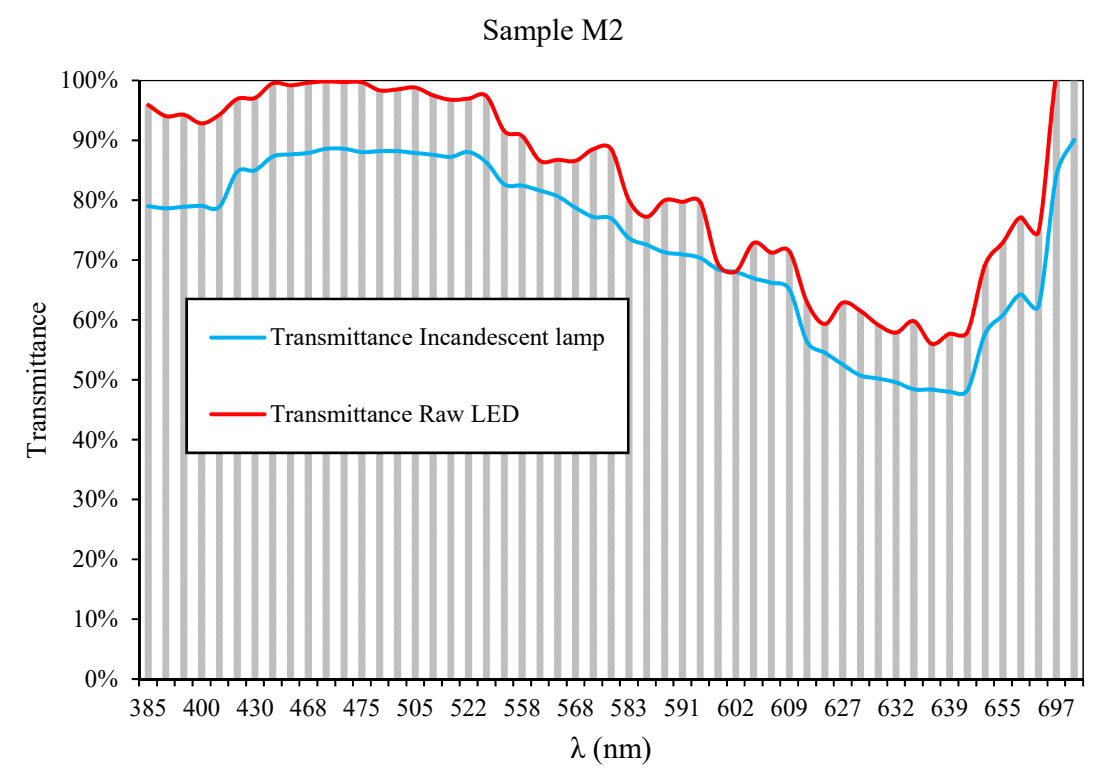

Figure 7. Comparison of the transmittance values obtained by a $5 \mathrm{~mm}$ LEDs spectral and those obtained by means of the commercial equipment.

Moreover, the emission intensity of the LED plays a fundamental role in determining the transmittance values. Values which are too low could make the photons not pass correctly through a water sample with a certain turbidity. In contrast, too high a value would cause the saturation of the sensor, making the reading impossible. In conclusion, all these questions require the definition of a calibration process that compensates for this deviation in results.

\subsection{LED Calibration}

\subsubsection{Brightness Level Selection}

When working with LEDs with different properties and from several manufacturers, it is not always possible to use a common brightness level for all of them. Each LED has different lighting capacities (Luminous Intensity) determined by its manufacturing process, in such a way that two different LEDs, powered by the same voltage and current can emit different brightness intensities. Therefore, if we change this current, we can also obtain different brightness levels.

If we take a known sample (M1), at different brightness levels with an LED of a certain peak wavelength (e.g., $385 \mathrm{~nm}$ ), in Figure 8 we observe that the transmittance values remain constant between $68 \%$ and $70 \%$, which corresponds to the brightness level obtained through a current from $0.073 \mathrm{~mA}$ to $2.051 \mathrm{~mA}$. With high luminescence LEDs, at low currents, we achieve an enough brightness level to carry out the analysis of the samples. In this range of values, the transmittance values experiment little variation. As commented, the transmittance value is higher than the reference value of $54.35 \%$, measured with the commercial equipment [31]. 


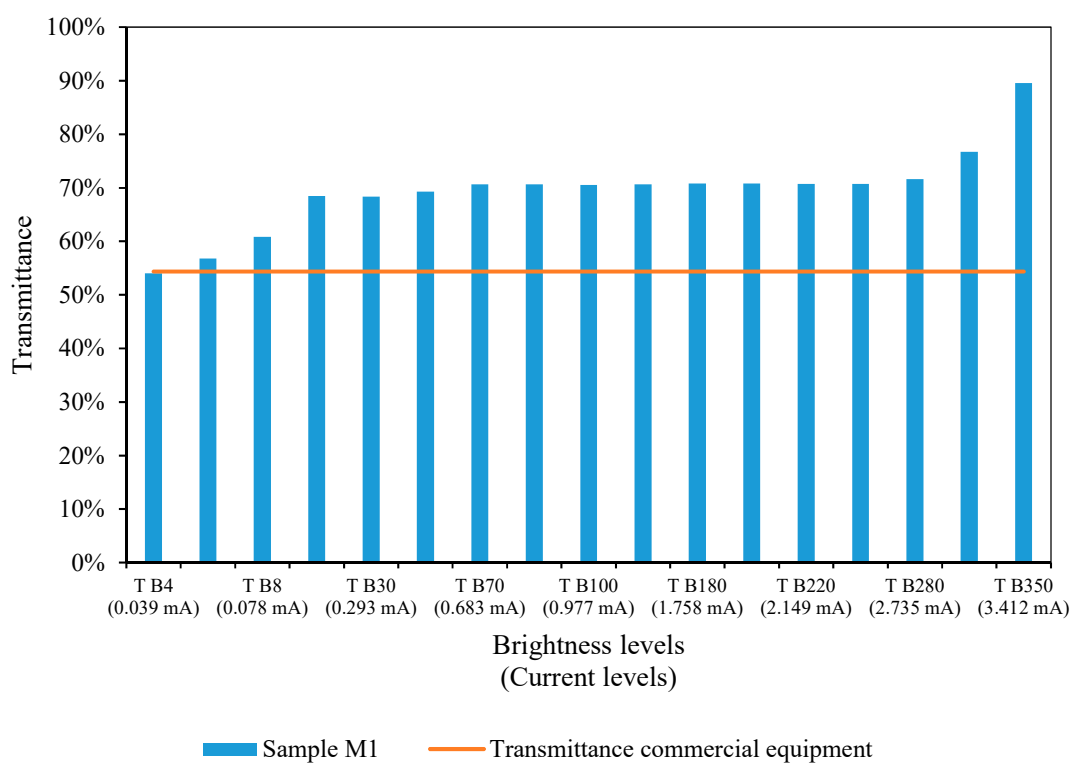

Figure 8. Effects of the brightness level in the transmittance measurement, using a $385 \mathrm{~nm}$ LED [30] on Sample M1.

Each LED is able to emit at a maximum brightness level, determined by the manufacturer using the "Luminous Intensity" parameter, which is usually expressed in mcd (millicandelas) or lumens. In the case of the $385 \mathrm{~nm}$ LED used [30], its maximum luminous intensity is $100 \mathrm{mcd}$. Measuring the brightness level of the LED would require the use of expensive and complex equipment such as lux meters. Therefore, we have associated the brightness level with the current applied to the LED, which is a parameter that can be easily measured without having to use any additional equipment.

The current level selected must be within a certain range to achieve a stable transmittance value, even if it is greater than the expected one. As shown in Figure 3, the intensity at which the different wavelengths emit follows a normal distribution. The further away the wavelength is from the peak value, the lower its emission intensity. At low brightness values (low current), the effect of wavelengths is negligible. This can be seen in the transmittance value corresponding to brightness level 4 (T B4). We are using a 16-bit driver (a number between 0 and 4095) to control the current up $40 \mathrm{~mA}$, so that, the brightness level designed as "T B4", is obtained by applying a current of $0.039 \mathrm{~mA}$ $\left(\frac{4 \times 40 \mathrm{~mA}}{4095}=0.039 \mathrm{~mA}\right)$.

The transmittance value was $54 \%$, fairly close to the expected one of $54.35 \%$. However, although the results are close, such a low level of brightness is unsuitable for spectrophotometry operations. If the sample had a higher turbidity, photons could not pass through it. Therefore, the use of a current level within the stabilized values of transmittance is the best and most suitable option.

Although it is possible to select any current level lower than which causes the saturation of the sensor [35], it is highly recommended to select one which provides a response between $50-70 \%$ of the resolution of the sensor (with the distilled water sample). In our case, we are using a 16-bit resolution (or a number between 0 and 4095), that is, an $I_{0}$ value between 511 and 716 (i.e., 2.5 and $3.5 \mathrm{~V}$ ). This is the criterion followed here. In Figure 8 it would correspond to brightness levels between TB30 and TB280, i.e., $0.293 \mathrm{~mA}$ and $2.735 \mathrm{~mA}$.

\subsubsection{Sensor Selection}

We observe from Figure 2 that photodiode OSD15-E (Figure 2B) presents, for example, at $470 \mathrm{~nm}$, a reference value $I_{0}$, (measured with a test-tube of distilled water), higher than S1223-01 (Figure 2A), since OSD15-E has a sensitivity greater than $50 \%$, while S1223 barely manages to reach $25 \%$.

However, the sensitivity of the sensor is not a critical parameter. If the reference value $\left(I_{0}\right)$ is greater, the light intensity crossing the sample to be analyzed $(I)$, will increase proportionally. Therefore, 
the transmittance value $\left(T=\frac{I}{I_{0}}\right)$ will remain constant regardless of the type of sensor used. Based on the tests carried out, we can say that this statement is true provided that the sensor has a sensitivity of at least $5 \%$ for the wavelength to be analyzed. Finally, the selected photodiode was S1223-01, with a monetary cost three times lower than OSD15-E.

\subsubsection{Peak Value Calibration}

In preliminary tests, each LED was only used to obtain the transmittance for a unique value of wavelength, its peak wavelength. A linear relation is observed between the transmittance values registered with the LED and those corresponding to its $\lambda_{\text {peak }}$ from the reference equipment, as shown in Figure 9. The calibration of the peak value of the LED always produces a better fit, above $98 \%$, as it is the highest wavelength intensity emitted by LED.

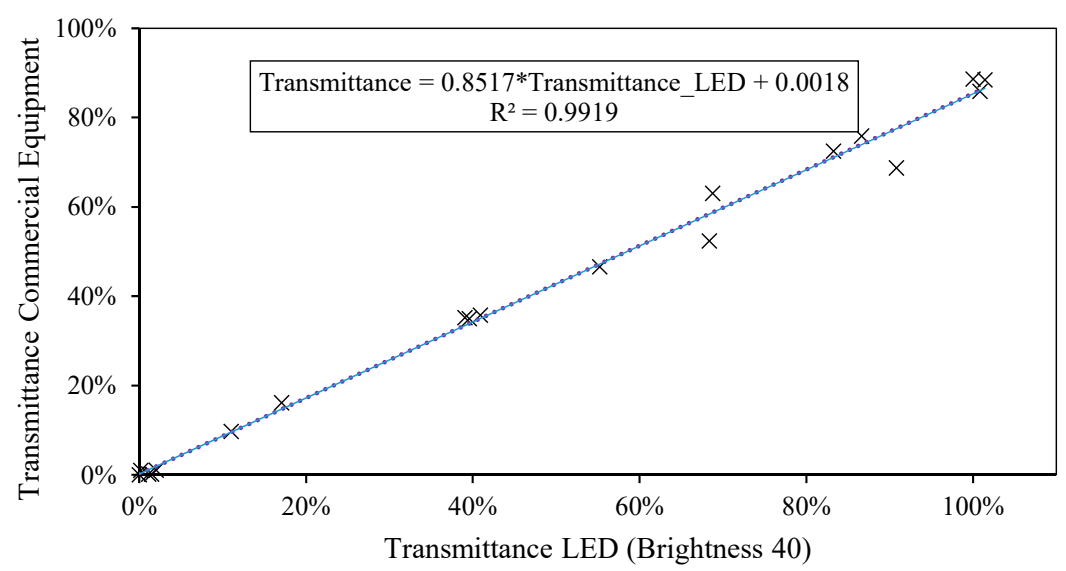

Figure 9. Scatter diagram between reference transmittance value and the most suitable brightness level (T40).

After the fit, in Figure 10 we can observe good agreement between the reference values of transmittance obtained by the commercial equipment and those measured with a limited-bandwidth LED after the calibration process. To make it easier for the reader to follow, the samples have been ordered in an increasing way, according to the transmittance values obtained with the commercial equipment.

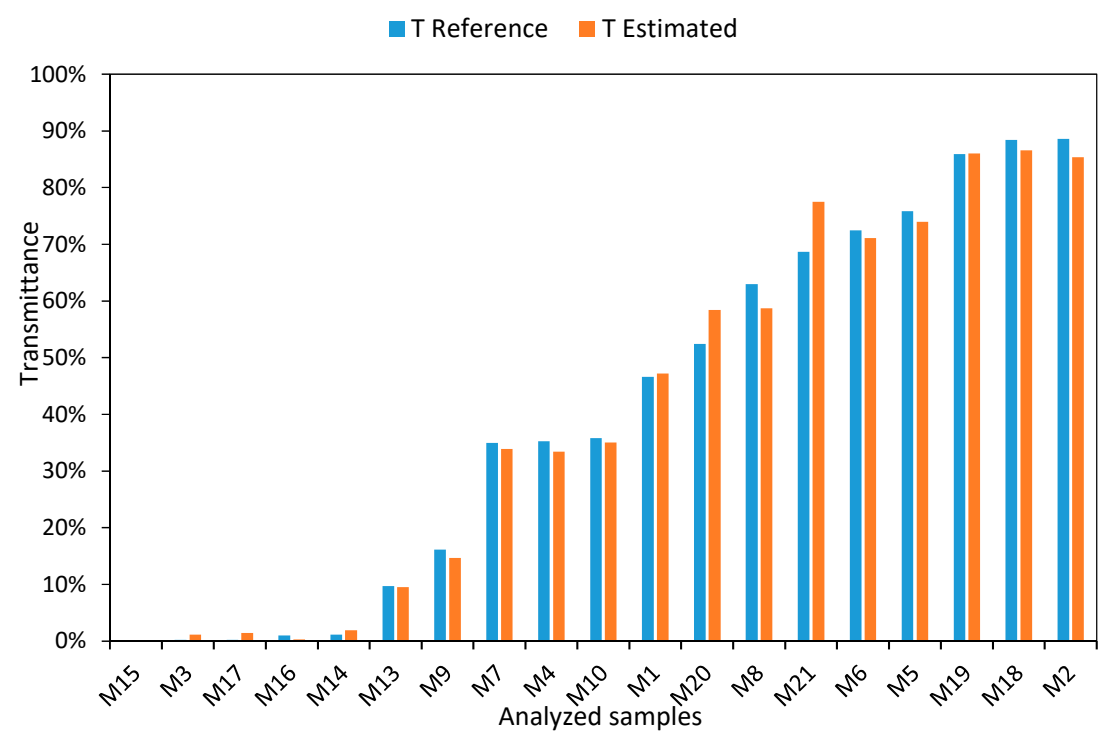

Figure 10. Comparison of calibration equations for $470 \mathrm{~nm}$ wavelength and brightness level 40. 


\subsubsection{Extension of the Working Range}

In this section, we show how it is possible to use the spectral width of an LED to model the transmittance of other wavelengths in addition to that of the peak value.

The tests carried out showed that the portion of the spectrum that can be used to extend the working range of a spectrophotometer is defined by those wavelengths between 10 and $20 \mathrm{~nm}$ over the peak value in the upper limit and the lower spectral width limit (LSWL). The LSWL is a parameter defined by the manufacturer (Table A1). These limits have been shown in Figure 11, using the LED with a $470 \mathrm{~nm}$ peak wavelength, as an example only.

(RELATIVE LUMINOUS INTENSITY)

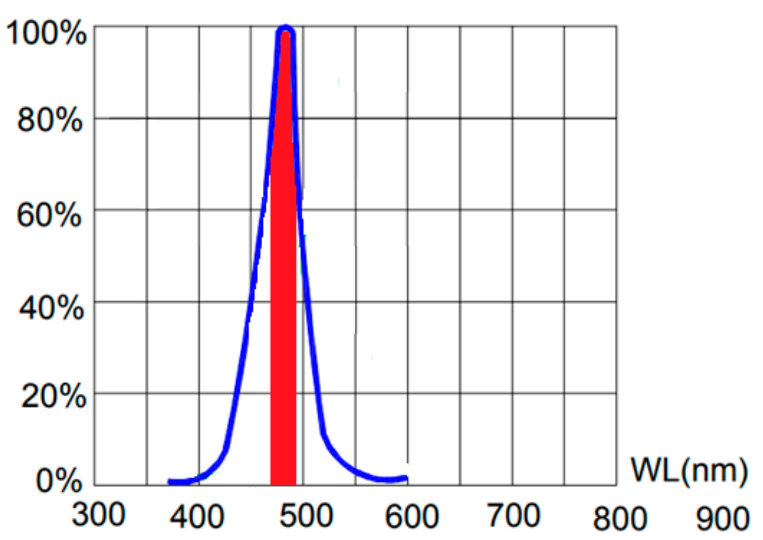

Figure 11. Representation of the useful working range of the $470 \mathrm{~nm}$ peak wavelength LED [36].

As shown in Equation (1), despite being able to use the lower limit of the spectral width to calibrate the wavelengths, with a fit above $96 \%$, from tests carried out we recommend working about $10 \mathrm{~nm}$ above this lower limit, in order to achieve a fit above $98 \%$.

$$
\left\{\begin{aligned}
\lambda_{\text {LSWL }}<\lambda_{\text {peak }}<\lambda_{\text {peak }}+10 \sim 20 \mathrm{~nm}, & 0.96<R^{2}<0.99 \\
\lambda_{\text {LSWL }}+10 \mathrm{~nm}<\lambda_{\text {peak }}<\lambda_{\text {peak }}+10 \sim 20 \mathrm{~nm}, & 0.98<R^{2}<0.99
\end{aligned}\right.
$$

To illustrate this expression (1), we used an LED with a peak of $470 \mathrm{~nm}$ and a spectral width between 450 and $500 \mathrm{~nm}$ [36] to determine its spectrum working range. We start calibration at $450 \mathrm{~nm}$ wavelength, which represents the lower limit of the spectral width of the $470 \mathrm{~nm}$ LED, and represents the most unfavorable situation.

As seen in Figure 12, the trend is similar in both graphs [37]. Although some irregularities are presented in the scatter diagram of Figure 13, the goodness of the resulting fit is greater than $97 \%$, showing that it is possible to use the portion of the spectrum included between the peak value of the LED and the lower limit of the spectral width. Extending this lower limit beyond that point will mean that the quality of the correlations will also be affected. If we take into account that the purpose of this calibration process is the development of spectrophotometric equipment with a comparable quality to the commercial one, a fit of lower than $97 \%$ is not desirable. Therefore, a wavelength placed $10 \mathrm{~nm}$ above the LWSL is recommended as being the lower transmittance capable that can be accurately reproduced by its corresponding $\lambda_{\text {peak }}$ LED. 


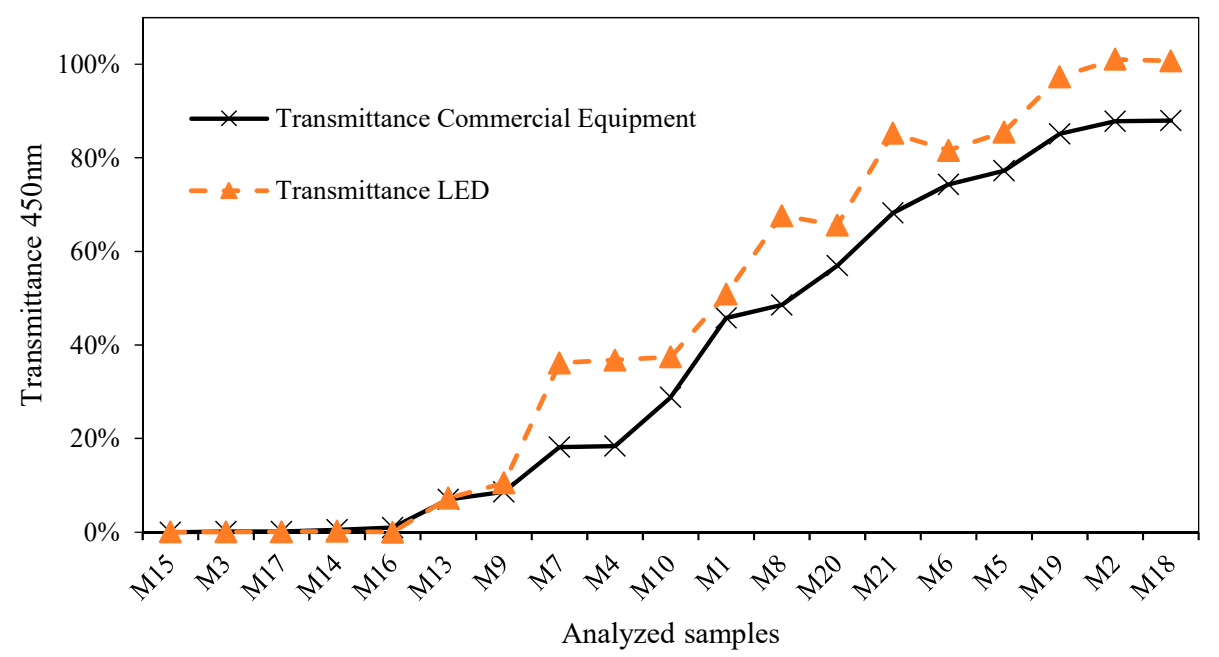

Figure 12. Comparison of transmittance obtained at $450 \mathrm{~nm}$ with the commercial equipment and the prototype developed based on an LED of dominant wavelength of $470 \mathrm{~nm}$.

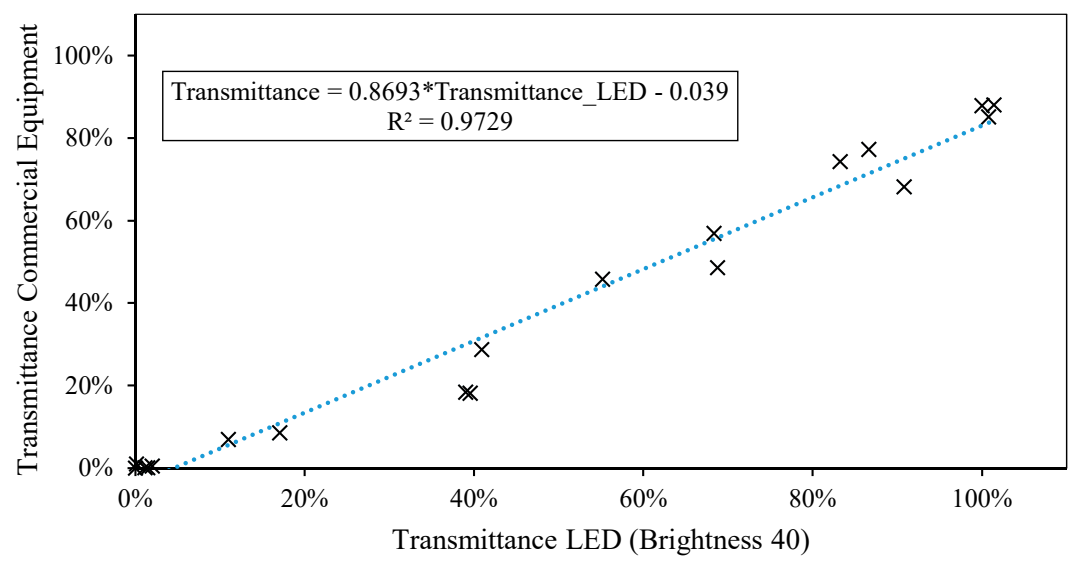

Figure 13. Scatter diagram between transmittance reference value at $450 \mathrm{~nm}$ and the most suitable brightness level (T40).

Figure 14 compares the transmittance values measured by LED after being correlated by the linear regression presented in Figure 13, and the transmittance values obtained with the reference equipment, where quite good agreement is observed. If we graphically represent the transmittance values calculated by this model, for very small values $\left(T_{B 40}<0.0448\right)$, negative values are obtained, which makes no sense from the physical point of view. Therefore, this has been adopted as a criterion to consider any negative result as zero. This is adequate if we consider that the sample M14 had a reference transmittance value of 0.005 . To make it easier for the reader to follow, the samples have been ordered in an increasing way, according to the transmittance values obtained with the commercial equipment.

It is also clear that wavelengths between this lower limit of the spectral width $(450 \mathrm{~nm})$ and the peak value can also be calibrated using the $470 \mathrm{~nm}$ LED, achieving an improvement in the goodness-of-fit as we approach the peak wavelength.

A certain $\lambda$ can be calibrated through different LEDs, as long as it is included within its spectral width. Table 2 shows the case for the wavelength of $445 \mathrm{~nm}$ obtained with LEDs with different $\lambda_{\text {peak }}$. 


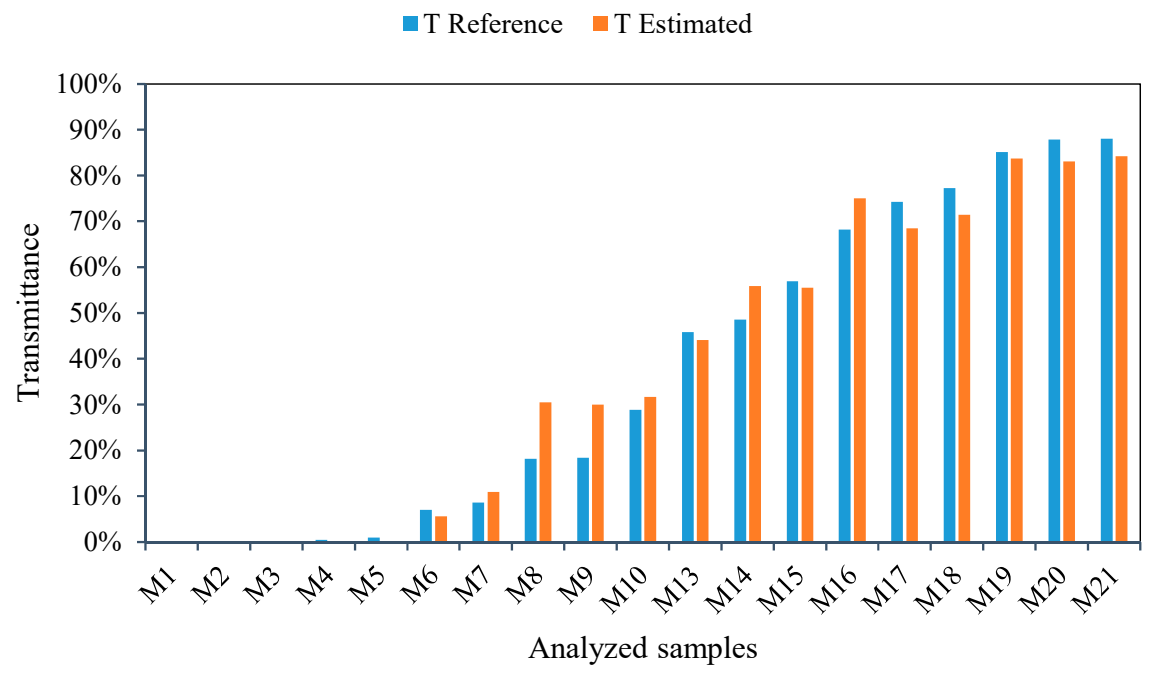

Figure 14. Comparison of calibration equations for $450 \mathrm{~nm}$ wavelength.

Table 2. $445 \mathrm{~nm}$ fit quality comparison using different LEDs.

\begin{tabular}{cccc}
\hline$\lambda$ & $\lambda_{\text {peak }}$ LED & $\boldsymbol{R}^{2}$ & Calibration Equation \\
\hline \multirow{4}{*}{$445 \mathrm{~nm}$} & $428 \mathrm{~nm}$ & 0.9924 & $\mathrm{y}=0.891 \mathrm{x}-0.0286$ \\
& $430 \mathrm{~nm}$ & 0.9927 & $\mathrm{y}=0.8868 \mathrm{x}-0.0298$ \\
& $435 \mathrm{~nm}$ & 0.9939 & $\mathrm{y}=0.8862 \mathrm{x}-0.0305$ \\
& $438 \mathrm{~nm}$ & 0.9971 & $\mathrm{y}=0.8853 \mathrm{x}-0.0304$ \\
& $440 \mathrm{~nm}$ & 0.9978 & $\mathrm{y}=0.8852 \mathrm{x}-0.0301$ \\
& $458 \mathrm{~nm}$ & 0.9803 & $\mathrm{y}=0.8847 \mathrm{x}-0.0314$ \\
& $461 \mathrm{~nm}$ & 0.9714 & $\mathrm{y}=0.8832 \mathrm{x}-0.0323$ \\
\hline
\end{tabular}

As expected, the best fit is achieved for the $440 \mathrm{~nm}$ LED; however, the $438 \mathrm{~nm}$ LED provides a very similar fit.

This raises the need to decide between calibrating a wavelength using an LED whose peak wavelength is the same (or very close) to that we seek to calibrate or using another LED that contains that wavelength in its spectral width. This is critical in order to be able to determine the effective working range of each diode. To illustrate this situation, we shall consider the calibration of an extreme case, the wavelength of $500 \mathrm{~nm}$, which is the upper limit of the spectral width of the $470 \mathrm{~nm}$ LED [36]. The study was also carried out with LED SSL-LX5093UEGC [38], with a peak wavelength of $500 \mathrm{~nm}$. The results are presented in Figure 15. This figure shows the comparison of the transmittance values obtained at $500 \mathrm{~nm}$ with LEDs of $470 \mathrm{~nm}$ and $500 \mathrm{~nm}$ of peak wavelength, before (Figure 15A) and after (Figure 15B) the calibration process. As can be seen, the results provided by the $500 \mathrm{~nm}$ LED are a closer fit to the reference values than those provided with the $470 \mathrm{~nm}$ LED. The first provides a fit of $98.97 \%$, compared to $74.68 \%$ obtained with the $470 \mathrm{~nm}$, which represents a worsening of $24 \%$. This is because $500 \mathrm{~nm}$ is located at the upper limit of the spectral width of the $470 \mathrm{~nm}$ LED, i.e., $30 \mathrm{~nm}$ away, and is therefore expected to provide a worse response than an LED with a peak wavelength closer to $500 \mathrm{~nm}$.

This result proves that we cannot use an LED whose peak wavelength is more than $30 \mathrm{~nm}$ from the one we seek to calibrate.

Nevertheless, as shown in Table 2, if the wavelength to be calibrated is at $20 \mathrm{~nm}$ or less with respect to the peak value of the LED (in the example from Table 2, $445 \mathrm{~nm}$ ) it is possible to obtain a high goodness-of-fit. Proof of that is the LED with a peak wavelength of $428 \mathrm{~nm}$, which can explain the $445 \mathrm{~nm}$ with an accuracy of $99 \%$. 
This shows that there is a limited capacity in terms of the wavelengths at which an LED can provide its spectral width. This process of verifying the useful spectral width of each LED has led us to the expressions shown in Equation (1).

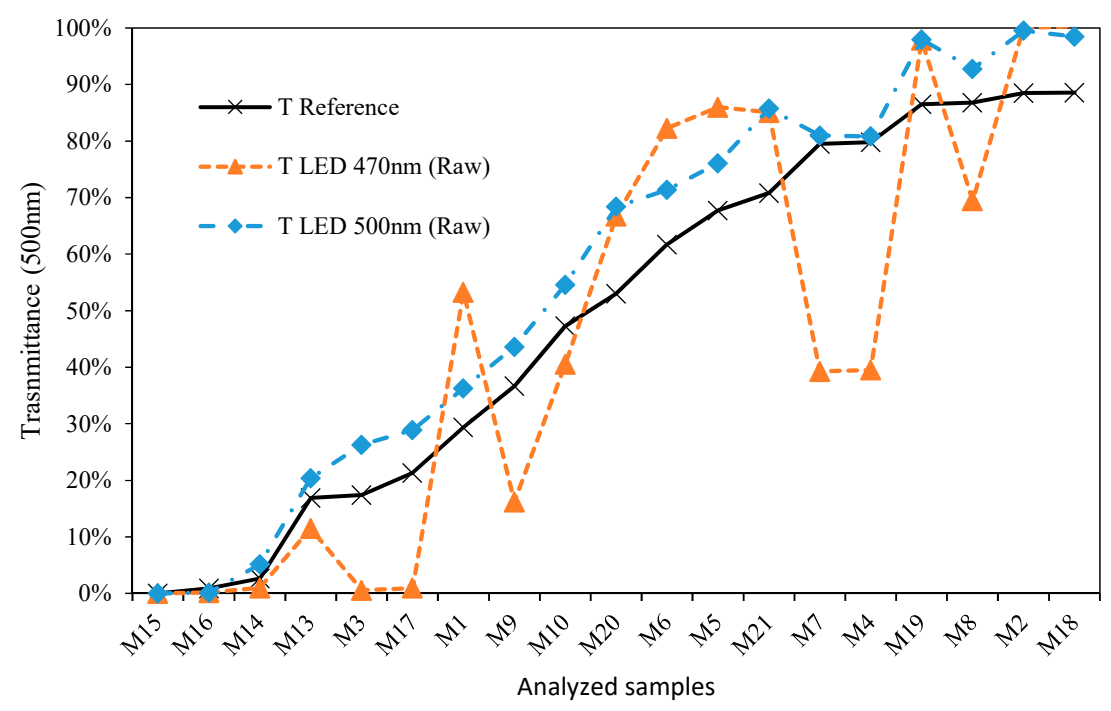

A

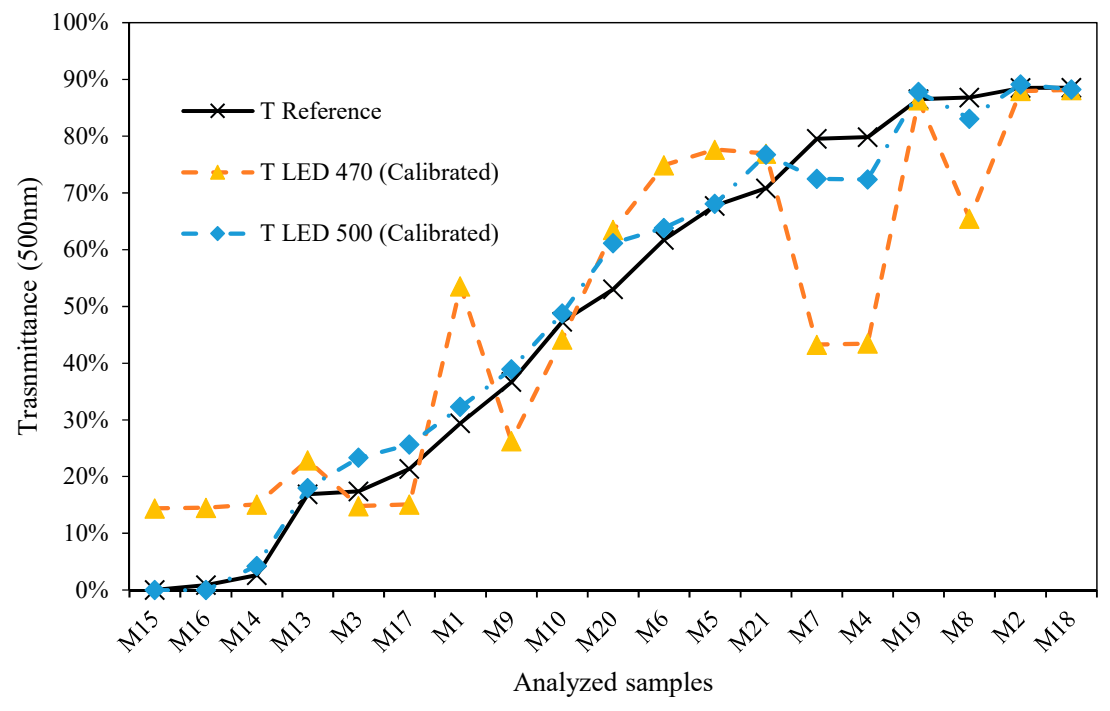

B

Figure 15. Comparison of the transmittance obtained at $500 \mathrm{~nm}$ with the commercial equipment and the prototype developed based on an LED with a peak wavelength of $470 \mathrm{~nm}$ and $500 \mathrm{~nm}$. (A) Before the calibration process. (B) After the calibration process.

\subsubsection{General Calibration Equation}

The need to calculate the calibration lines for each of the wavelengths that we wish to add to our own equipment can result in a tedious and inefficient task. Any extension of the working spectrum would require the acquisition of new data and their comparison with the expected transmittance values.

Nevertheless, it is possible to find a generic expression that allows us to fit each of the desired wavelengths, independently of the LED used, as long as it includes that wavelength within its spectral width.

To illustrate the procedure followed to obtain generic calibration equations, all calibration lines calculated using the procedure described in the previous sections have been represented in Figure 16. 
In the present work, only wavelengths between 380 and $700 \mathrm{~nm}$ have been calibrated at $5 \mathrm{~nm}$ intervals, although it is possible to extend this range and reduce the bandwidth to $1 \mathrm{~nm}$.
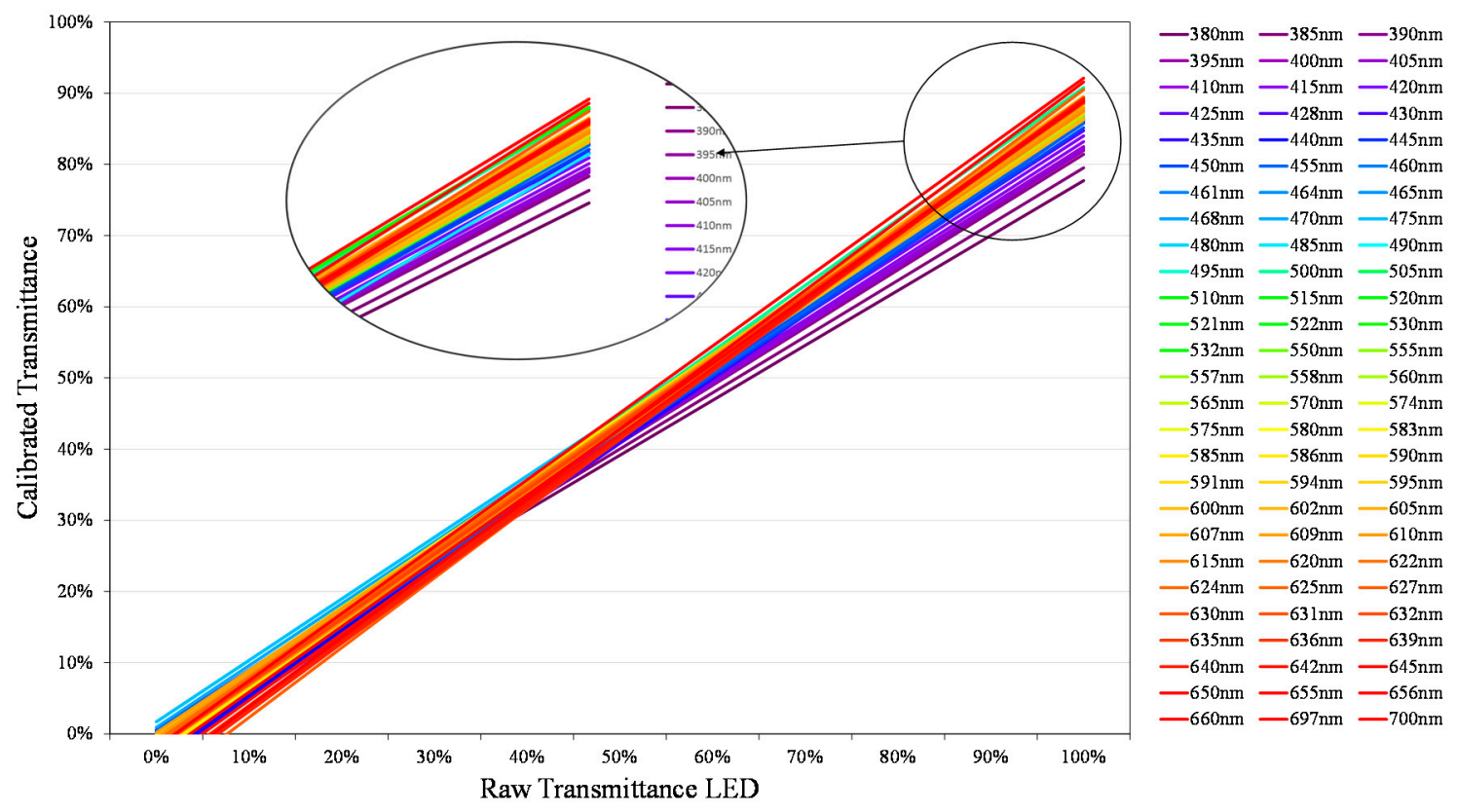

Figure 16. Calibration lines between 380 and $700 \mathrm{~nm}$.

For a better understanding, each of the calibration lines has been represented with the color of its wavelength.

The calibration lines have a slope that changes depending on the wavelength. In the enlarged view of Figure 16, it can be observed that these are distributed in a very close way to how the visible spectrum does it [39]. However, the way the slope evolves changes depending on the wavelength range being analyzed.

To understand the behavior of the calibration lines (Figure 16), Figure 17 shows the transmittance values that would be obtained just at the tipping point of most graphs. In other words, the point where all the LEDs would provide a transmittance value (before calibration) of $50 \%$ for a certain sample. At this point, the behavior of the calibration lines of Figure 16 are most clearly observed.

As we can see in Figure 17, the graph forms groups. If we look at the wavelengths that delimit each group, we observe that these correspond to the different color groups that make up the visible light spectrum [40], the spectral limits of which are shown in Figure 18.

Based on these groups, we have determined the expressions that link the calibration line of Figure 16 to the wavelength. In the following we show only the procedure for determining the corresponding generic calibration equation for the "Blue" color group (427-476 nm), by means of an example.

Table 3 shows the calibration lines calculated for the wavelengths corresponding to the color blue, that is to say, between 427 and $480 \mathrm{~nm}$, at intervals of $5 \mathrm{~nm}$. When we work with a linear model (Figures 9,13 and 16), the only parameters we need to estimate as a function of the wavelength are the slope $m$ and the ordinate at the origin $n$.

Through a scatter plot, it is possible to obtain the trend line that relates both parameters with respect to the value of $\lambda$. The results are shown in Figure 19.

Both the slope $m$ and the ordinate at the origin $n$ can be defined as a line whose slope depends on the wavelength we seek to calculate (Figure 19A,B). As shown in Figure 19C,D, the values of $m^{\prime}$ and $n^{\prime}$ calculated using this model are very close to the values obtained empirically using the manual calibration procedure, described in the previous sections. 


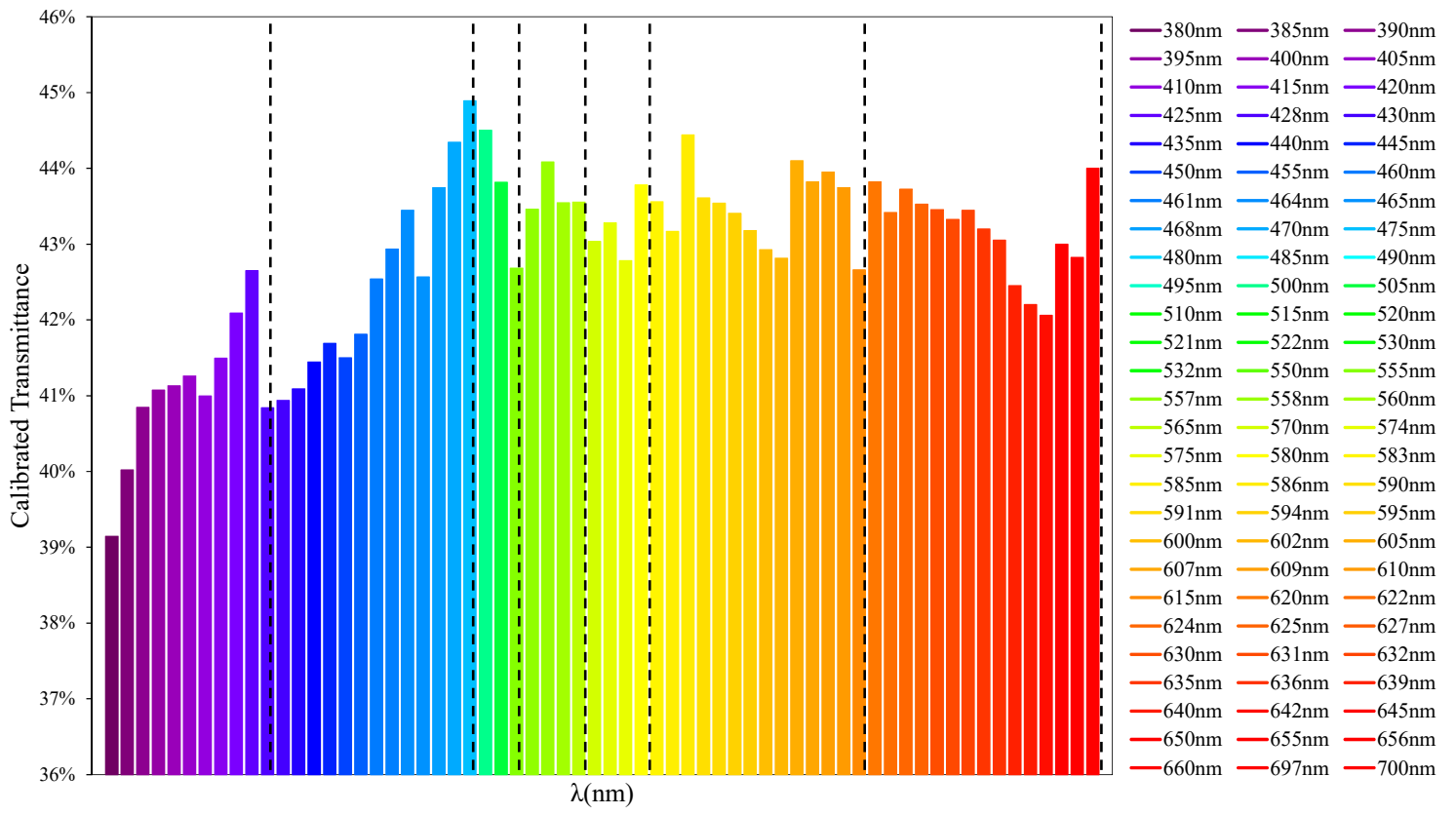

Figure 17. Transmittance values calculated at the tipping point of the calibration lines of Figure 16. Transmittance LED 50\%.

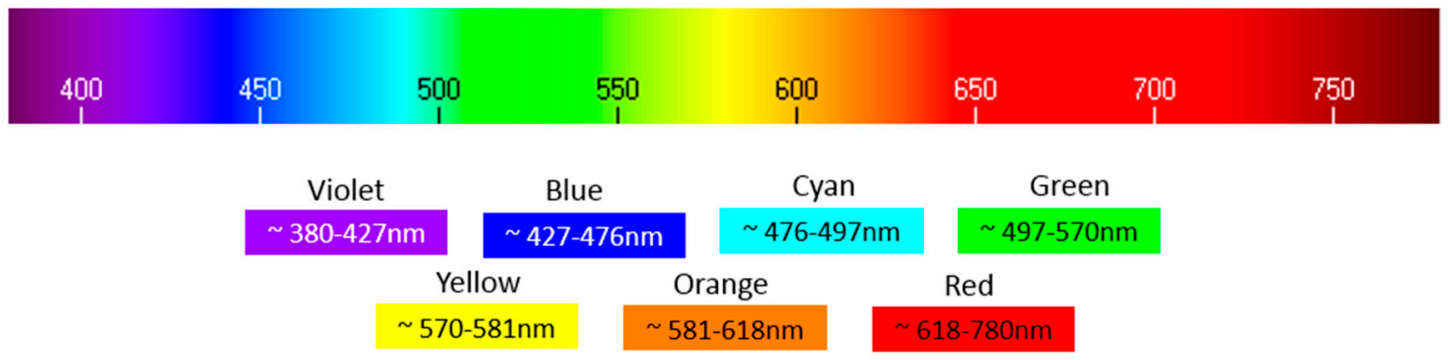

Figure 18. Visible light color spectrum.

Table 3. Calibration straight lines between 427 and $480 \mathrm{~nm}$ (Blue).

\begin{tabular}{ccccc}
\hline$\lambda$ & Calibration Equation & $m$ & $n$ & $\boldsymbol{R}^{2}$ \\
\hline 428 & $\mathrm{y}=0.9004 \mathrm{x}-0.0418$ & 0.9004 & -0.0418 & 0.9892 \\
430 & $\mathrm{y}=0.8985 \mathrm{x}-0.0399$ & 0.8985 & -0.0399 & 0.9906 \\
435 & $\mathrm{y}=0.9 \mathrm{x}-0.0391$ & 0.9 & -0.0391 & 0.9911 \\
440 & $\mathrm{y}=0.8973 \mathrm{x}-0.0342$ & 0.8973 & -0.0342 & 0.9917 \\
445 & $\mathrm{y}=0.891 \mathrm{x}-0.0286$ & 0.891 & -0.0286 & 0.9924 \\
450 & $\mathrm{y}=0.8728 \mathrm{x}-0.0214$ & 0.8728 & -0.0214 & 0.9918 \\
455 & $\mathrm{y}=0.879 \mathrm{x}-0.0214$ & 0.879 & -0.0214 & 0.9941 \\
460 & $\mathrm{y}=0.8738 \mathrm{x}-0.0115$ & 0.8738 & -0.0115 & 0.9973 \\
461 & $\mathrm{y}=0.8665 \mathrm{x}-0.0039$ & 0.8665 & -0.0039 & 0.9986 \\
464 & $\mathrm{y}=0.8621 \mathrm{x}+0.0034$ & 0.8621 & 0.0034 & 0.9981 \\
465 & $\mathrm{y}=0.8747 \mathrm{x}-0.0117$ & 0.8747 & -0.0117 & 0.9972 \\
468 & $\mathrm{y}=0.8753 \mathrm{x}-0.0002$ & 0.8753 & -0.0002 & 0.9978 \\
470 & $\mathrm{y}=0.8685 \mathrm{x}+0.0092$ & 0.8685 & 0.0092 & 0.9953 \\
475 & $\mathrm{y}=0.864 \mathrm{x}+0.0169$ & 0.864 & 0.0169 & 0.9875 \\
480 & $\mathrm{y}=0.8537 \mathrm{x}+0.0265$ & 0.8537 & 0.0265 & 0.9628 \\
\hline
\end{tabular}

From these data, it is possible to determine the expression that allows us to correlate the transmittance results obtained by the commercial equipment with respect to the values obtained by an LED, according to the wavelength. 


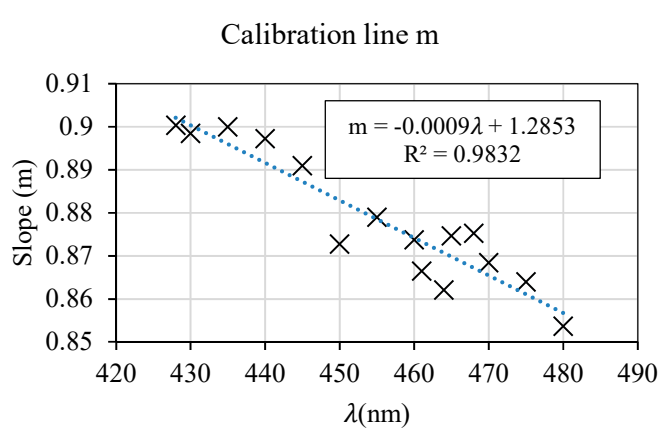

(A)

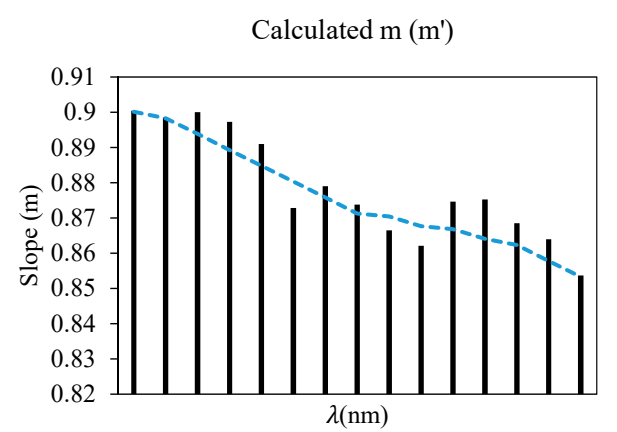

(C)

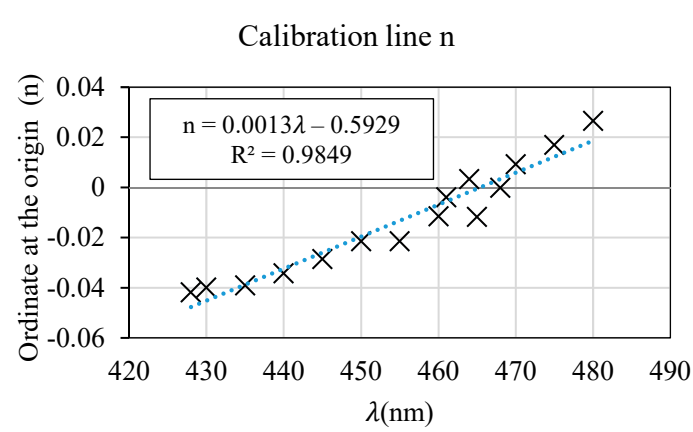

(B)

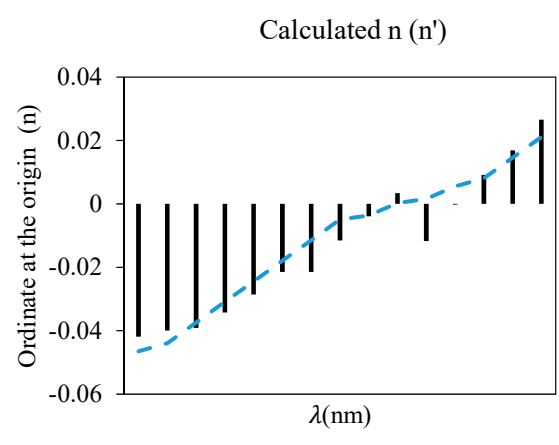

(D)

Figure 19. Calculation of the trend lines of the slope $m$ and the ordinate at origin $n$ according to $\lambda$. $(\mathbf{A}, \mathbf{B})$ are the scatter graphs used to enable the regression line (model) for the slope $m$ and the ordinate at origin $n$ to be calculated. (C,D) show the $m$ and $n$ values calculated through that model.

In Equation (2), the generic calibration equations are shown for each of the color groups shown in Figure 18. It is important to emphasize that although the red color is up to $780 \mathrm{~nm}$, we have only made the calibration up to $700 \mathrm{~nm}$, since we do not have LEDs that emit at those wavelengths.

$$
\begin{gathered}
y_{380-427 n m}=(0.0013 \lambda+0.2941) * T \\
y_{427-480 \mathrm{~nm}}=(-0.0009 * \lambda+1.2853) * T+(0.0013 * \lambda-0.5929) \\
y_{480-497 \mathrm{~nm}}=(-0.00001 * \lambda+0.9198) * T+(0.0043 * \lambda-2.1638) \\
y_{497-570 \mathrm{~nm}}=(-0.0004 * \lambda+1.1273) * T+(0.0002 * \lambda-0.1245) \\
y_{570-581 \mathrm{~nm}}=(0.0578 * \lambda-32.296) * T+(0.0221 * \lambda+12.652) \\
y_{581-618 \mathrm{~nm}}=(-0.018 * \lambda+11.677) * T+(-0.0032 * \lambda+1.8929) \\
y_{618-700 \mathrm{~nm}}=(0.0006 * \lambda+0.5462) * T+(-0.0001 * \lambda+0.0277)
\end{gathered}
$$

\subsection{Results}

Using the calibration procedure described above, it is possible to achieve results very close to those obtained by using commercial equipment based on incandescent lamps.

This section shows the measured transmittance values for samples of different types and concentrations, along with the values provided by the commercial equipment.

As can be seen in Figure 20, there is good agreement between the two charts. Furthermore, each of the comparative graphs has been accompanied by the transmittance values obtained before the calibration process, in order to show the deviation in the results. This demonstrates that the calibration process described in the previous sections can produce results comparable to those obtained with incandescent lamps. 


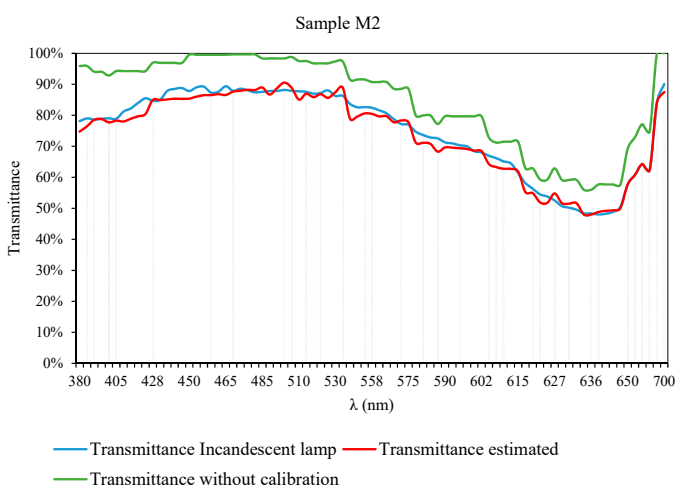

(A)

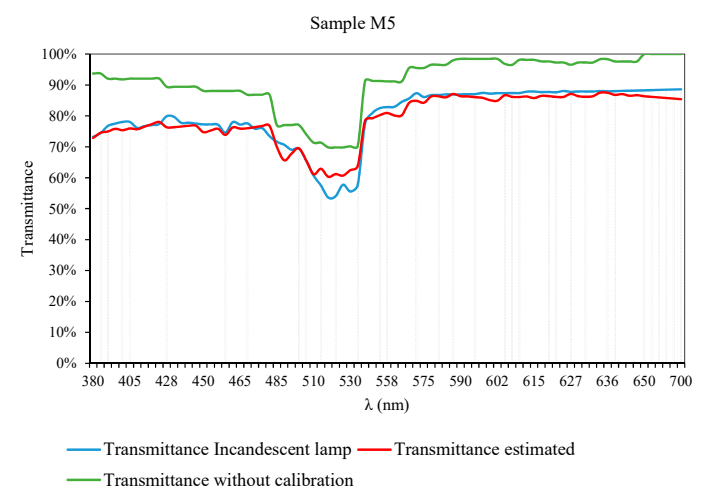

(C)

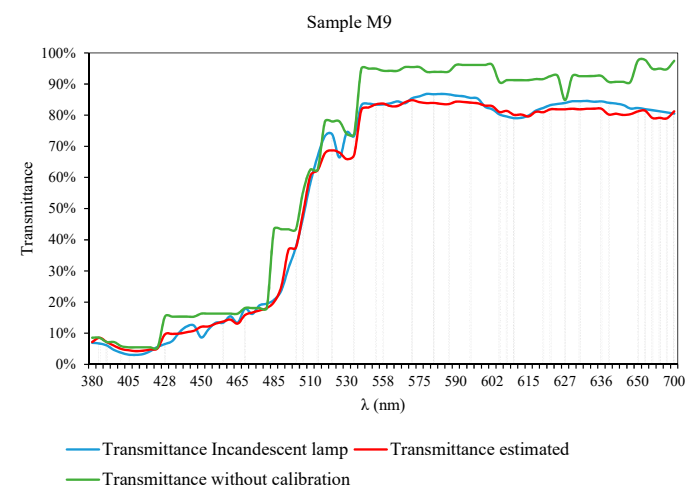

(E)

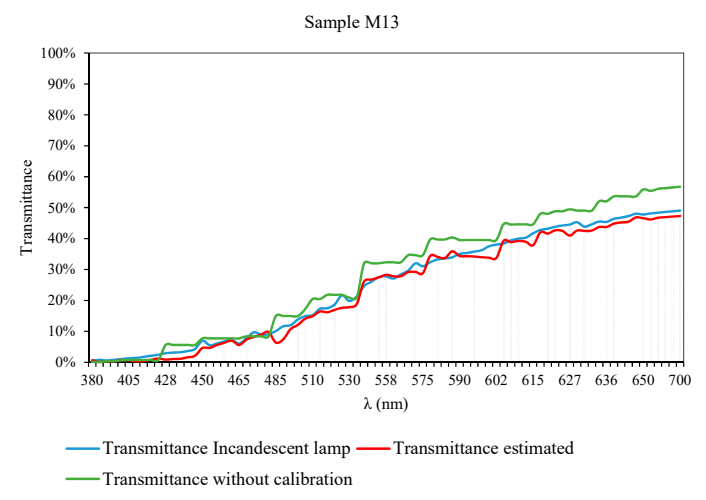

(G)

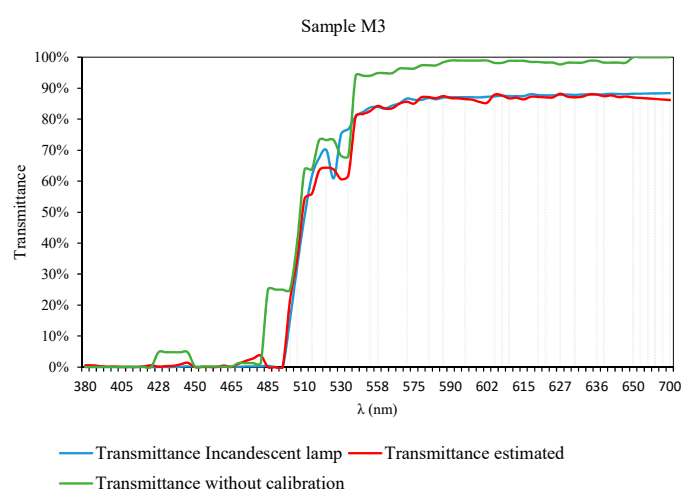

(B)

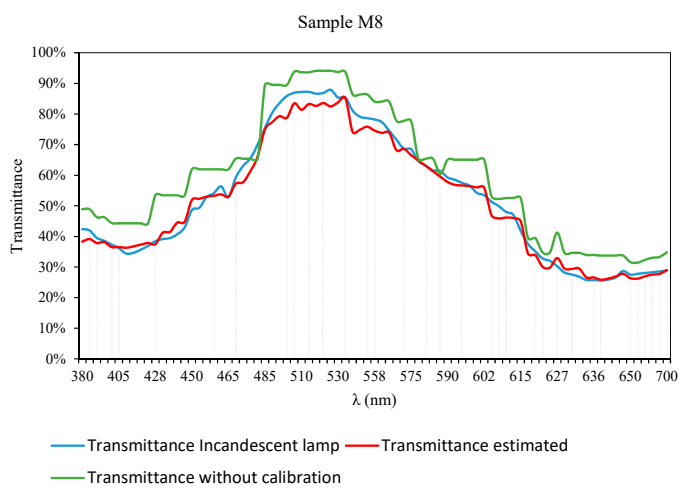

(D)

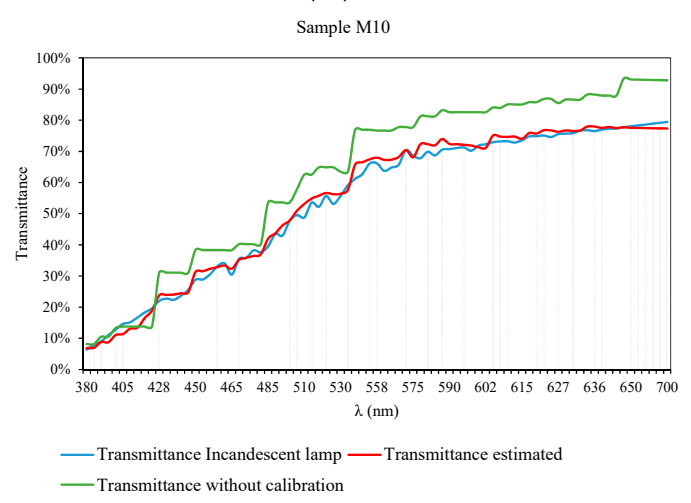

(F)

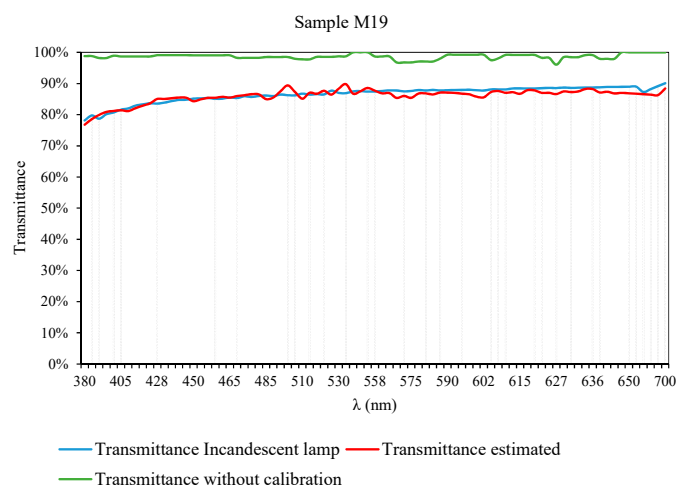

(H)

Figure 20. Comparative results of the transmittance values, before (green) and after (red) the calibration process for the following samples: (A) M2, (B) M3, (C) M5, (D) M8, (E) M9, (F) M10, (G) M13 and (H) M19. 
If we pay attention to Figure 20B-E, we observe that for wavelengths between 510 and $550 \mathrm{~nm}$ (which correspond to the green color spectrum) there are certain irregularities.

Such irregularity is due to the fact that after the calibration process, the fit was $96 \%$, while the rest of the wavelengths obtained values above $98 \%$.

This problem is probably due to the fact that the LEDs used to explain this region of the spectrum do not have the peak wavelength indicated by the manufacturer, since this problem has only been observed in the LEDs used for that wavelength range, whose peak wavelengths according to the manufacturer are $515,531,532$, and $550 \mathrm{~nm}$, respectively.

In each of the results graphs, the wavelength range explained by each of the 34 LEDs used after the calibration process has been delimited by vertical lines. Each vertical line presents an LED with a different peak wavelength.

The samples used to carry out the calibration process are representative of the transmittance values that can be presented by samples of wastewater from sewage networks. The wastewater samples can have transmittance values between 20-90\% [41]. To show the adequacy of the calibration system, Figure 21 includes the results of the analysis performed with a sample of wastewater obtained from a treatment plant, which does not belong to the list of samples (Table 1) used during the calibration process.

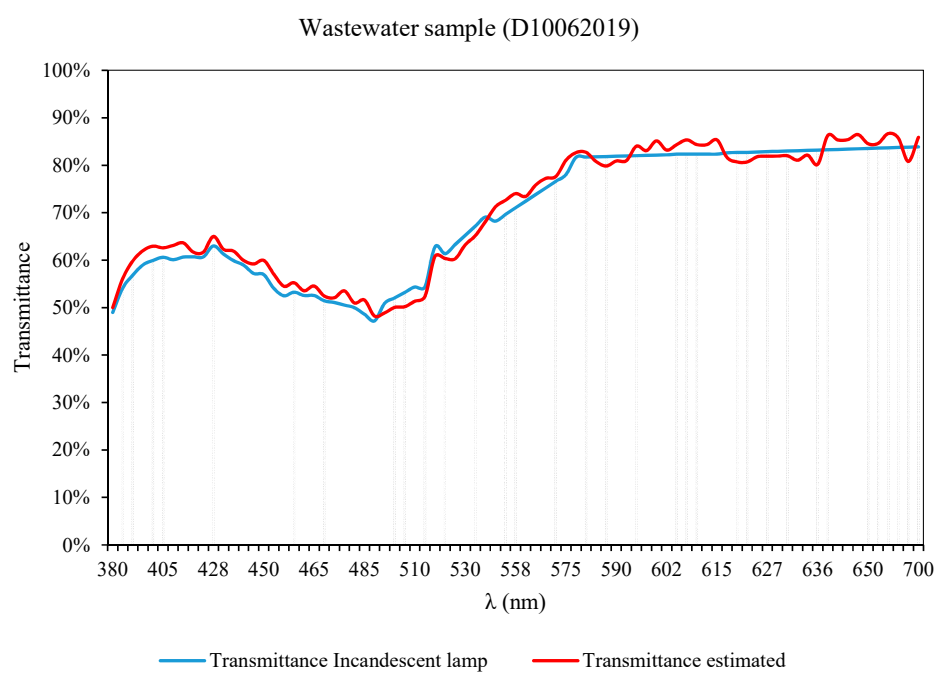

Figure 21. Wastewater sample analysis (D10062019).

In view of the results, it is possible to obtain a response comparable to that obtained by expensive commercial equipment based on incandescent lamps, through the use of LED technology, after a calibration process.

Several statistical indicators have been calculated to enable an analysis of how well the calibration process works. The quadratic mean error (RMSD) [42], and the error index, $E r$, are calculated according to Equations (3) and (4). These were calculated in the wavelength range of 380 to $700 \mathrm{~nm}$, as seen previously in Figure 20.

$$
\begin{aligned}
& R M S D=\sqrt{\frac{1}{n} \sum_{i}^{n}\left(T_{\text {measured_i } i}-T_{\text {calculated_ } i}\right)^{2}} \\
& E r(\%)=\left\|\frac{\sum_{i}^{n}\left(T_{\text {measured_i }}-T_{\text {calculated_i } i}\right)}{\sum_{i}^{n} T_{\text {measured_i }} i} * 100\right\|
\end{aligned}
$$

where $E r$ is the error index (\%); $n$ is the number of wavelength (in our case, it takes the value of 81 ); $T_{\text {measured }}$ and $T_{\text {calculated }}$ are the values of transmittance obtained through the commercial equipment [31] and own design based on LED technology (Figure 5), respectively. 
As we can see in Table 4, we obtained an RMSD very close to zero for all the samples. This shows that the transmittance values obtained through commercial equipment and those obtained through the calibration process described in this research work are very close to each other.

Table 4. RMSD and Error index.

\begin{tabular}{ccc}
\hline Sample & RMSD & $\boldsymbol{E r} \mathbf{( \% )}$ \\
\hline M2 & 0.02062086 & 1.451423749 \\
M3 & 0.028591905 & 0.962997523 \\
M5 & 0.024032501 & 0.990803799 \\
M8 & 0.027103038 & 2.135421037 \\
M9 & 0.023634811 & 1.473856032 \\
M10 & 0.019272554 & 1.426693178 \\
M13 & 0.017883052 & 4.921374084 \\
M19 & 0.013081104 & 0.986143228 \\
D10062019 & 0.020993826 & -1.152994953 \\
\hline
\end{tabular}

Proof of this lies in the error values, Er. For all the samples, the error has always been lower than $5 \%$, and in almost all cases was less than $1 \%$. That is an error index comparable to that the equipment based on incandescent lamps.

It should be noted that not all the LEDs used have taken full advantage of their useful spectral width. Although the range of the spectral width shown in Equation (1) ensures us a goodness-of-fit above $97 \%$, it has been chosen not to take all the range of the diodes, using more LEDs in order to achieve a fit close to $99 \%$. This has resulted in a total of 34 LEDs to calibrate 81 wavelengths.

\section{Conclusions}

In this paper, we have shown that it is possible to use LED technology as a replacement for traditional incandescent lamps, for the development of spectrophotometers. To achieve this, it is necessary to carry out a calibration process the compensate for the effect produced by the multiple wavelengths that the LEDs emits at the same time (spectral width).

Therefore, we can conclude that the calibration procedure described enables us to achieve results comparable to those obtained by incandescent lamps. Proof of that lies in the fact that the error obtained has been less than $5 \%$, and was around $1 \%$ in most cases analyzed (Table 4 ).

The methodology proposed allows us to:

(i) Obtain results comparable to those provided by commercial equipment based on incandescent lamps, without using any type of optical elements such as lenses or diffraction matrix that would make the equipment more expensive;

(ii) Extend the working range of each LED, covering the whole visible spectrum using a smaller number of LEDs;

(iii) Reduce the dimensions, costs and sampling times of the equipment, which are vital aspects for the development of low-cost autonomous systems designed to measure in any type of environment.

This calibration procedure allows anyone to develop their own spectrophotometry equipment. This means that everyone can have access to this type of equipment at a small fraction of the cost of commercial equipment.

This procedure has enabled us to achieve a working range between 380 and $700 \mathrm{~nm}$ by using just 34 LEDs that cover different areas of the visible spectrum, with a resolution of $5 \mathrm{~nm}$.

That opens the door to the development of new systems based on this technology, lowering the cost of equipment while reducing its size and consumption, enabling the creation of autonomous equipment that can run on batteries in any environment. 
This type of systems can be very useful for the detection of unauthorized discharges, as the system can be placed in any environment, monitoring $24 \mathrm{~h}$ a day. It is therefore a tool against fraud and can contribute to environmental protection.

All this research work will allow us to have real-time control of water quality in sewer systems during rainfall events and dry weather periods, through a portable and cost-effective device to analyze the contaminant load present in wastewater.

Author Contributions: Investigation, D.C.-P. and J.T.G.; Data curation, D.C.-P.; Formal analysis, D.C.-P., J.T.G., F.C.-C. and J.S.-M.; Funding acquisition, D.C.-P., J.T.G. and J.S.-M.; Methodology, D.C.-P., J.T.G., F.C.-C. and J.S.-M; Software, D.C.-P. and F.C.-C.; Supervision, D.C.-P., J.T.G., F.C.-C. and J.S.-M; Validation, J.T.G., F.C.-C. and J.S.-M; Writing-original draft, D.C.-P. and J.T.G.

Funding: This research was funded by Seneca Foundation of the Región de Murcia (Spain) and "Hidrogea, Gestión Integral de Aguas de Murcia S.A".

Acknowledgments: Authors wish to thank the financial support received from the Seneca Foundation of the Región de Murcia (Spain) through the program devoted for training of novel researchers in areas of specific interest for the industry and with a high capacity to transfer the results of the research generate entitled: "Subprograma Regional de Contratos de Formación de Personal Investigador en Universidades y OPIs" (Mod. B, Ref. 20320/FPI/17).

Conflicts of Interest: The authors declare no conflict of interest.

\section{Appendix A}

Table A1. LEDs used.

\begin{tabular}{|c|c|c|c|c|c|}
\hline \multirow{2}{*}{ ID } & \multirow{2}{*}{$\lambda_{\text {Peak }}(\mathrm{nm})$} & \multicolumn{2}{|c|}{ Spectral Width } & \multirow{2}{*}{ Reference } & \multirow{2}{*}{ Datasheet } \\
\hline & & Lower Limit (nm) & Upper Limit (nm) & & \\
\hline 1 & 385 & 360 & 400 & VAOL-5EUV8T4 & www.mouser.es \\
\hline 2 & 390 & 388 & 392 & UV5TZ-390-15 & www.mouser.es \\
\hline 3 & 395 & 393 & 398 & UV5TZ-395-15 & www.mouser.es \\
\hline 4 & 400 & 398 & 400 & UV5TZ-400-15 & www.mouser.es \\
\hline 5 & 405 & 395 & 415 & VAOL-5EUV0T4 & www.mouser.es \\
\hline 6 & 428 & 400 & 440 & $4304 \mathrm{H} 6$ & www.mouser.es \\
\hline 7 & 461 & 440 & 480 & 151053BS04500 & www.mouser.es \\
\hline 8 & 468 & 456 & 480 & LTL2P3TBK5 & www.mouser.es \\
\hline 9 & 500 & 475 & 520 & SSL-LX5093UEGC & www.mouser.es \\
\hline 10 & 505 & 487 & 518 & LTL2V3TCYK2 & www.mouser.es \\
\hline 11 & 515 & 497 & 531 & WP7113ZGCK & www.eu.mouser.com \\
\hline 12 & 521 & 505 & 536 & HLMP-HM74-34CDD & www.broadcom.com \\
\hline 13 & 532 & 506 & 544 & LTL2P3TGZ2KS & www.mouser.es \\
\hline 14 & 557 & 543 & 575 & WP7113PGC & www.eu.mouser.com \\
\hline 15 & 558 & 500 & 570 & HLMP-C615-G0001 & www.broadcom.com \\
\hline 16 & 574 & 585 & 602 & TLCYG5100 & www.mouser.es \\
\hline 17 & 583 & 550 & 610 & $521-9466 \mathrm{~F}$ & www.mouser.es \\
\hline 18 & 586 & 565 & 615 & $521-9271 \mathrm{~F}$ & www.uy.mouser.com \\
\hline 19 & 594 & 587 & 600 & HLMP-EL1A-Z1KDD & www.broadcom.com \\
\hline 20 & 605 & 590 & 620 & SLI-580DT3F & www.mouser.es \\
\hline 21 & 607 & 581 & 623 & WP7113NC & www.kingbrightusa.com \\
\hline 22 & 609 & 600 & 618 & HLMP-EJ15-SV000 & www.mouser.es \\
\hline 23 & 622 & 612 & 632 & TLCR5200 & www.mouser.es \\
\hline 24 & 624 & 597 & 648 & C503B-RBN-CX0Y0AA1 & www.mouser.es \\
\hline 25 & 627 & 600 & 650 & WP57EYW & www.mouser.es \\
\hline 26 & 631 & 623 & 645 & 151053RS03000 & www.mouser.es \\
\hline 27 & 636 & 625 & 648 & SSL-LX5093SIC & www.eu.mouser.com \\
\hline 28 & 639 & 630 & 650 & LTL2H3KRK & www.mouser.es \\
\hline 29 & 650 & 635 & 663 & HLMP-4101 & www.mouser.mx \\
\hline 30 & 655 & 650 & 675 & WP7113SRC/DU & www.mouser.es \\
\hline 31 & 656 & 645 & 665 & VAOL-5GAE4 & www.eu.mouser.com \\
\hline 32 & 660 & 648 & 675 & LTL-4268-H3 & www.mouser.es \\
\hline 33 & 697 & 650 & 743 & LTL-4213 & www.digikey.com \\
\hline 34 & 700 & 655 & 730 & SSL-LX5093HD-TR & www.lumex.com \\
\hline
\end{tabular}




\section{References}

1. Thomas, O.; Burgess, C. (Eds.) UV-Visible Spectrophotometry of Water and Wastewater; Elsevier: Amsterdam, The Netherlands, 2017.

2. Bourgeois, W.; Burgess, J.E.; Stuetz, R.M. On-line monitoring of wastewater quality: A review. J. Chem. Technol. Biotechnol. Int. Res. Process Environ. Clean Technol. 2001, 76, 337-348. [CrossRef]

3. Chen, B.; Wu, H.; Li, S.F.Y. Development of variable pathlength UV-Vis spectroscopy combined with partial-least-squares regression for wastewater chemical oxygen demand (COD) monitoring. Talanta 2014, 120, 325-330. [CrossRef] [PubMed]

4. Brito, R.S.; Pinheiro, H.M.; Ferreira, F.; Matos, J.S.; Lourenço, N.D. In situ UV-Vis spectroscopy to estimate COD and TSS in wastewater drainage systems. Urban Water J. 2014, 11, 2612-2673. [CrossRef]

5. Hochedlinger, M.; Kainz, H.; Rauch, W. Assessment of CSO loads-based on UV/VIS-spectroscopy by means of different regression methods. Water Sci. Technol. 2006, 54, 239-246. [CrossRef] [PubMed]

6. Gruber, G.; Winkler, S.; Pressl, A. Quantification of pollution loads from CSOs into surface water bodies by means of online techniques. Water Sci. Technol. 2004, 50, 73-80. [CrossRef] [PubMed]

7. Gruber, G.; Bertrand-Krajewski, J.L.; Beneditis, J.D.; Hochedlinger, M.; Lettl, W. Practical aspects, experiences and strategies by using UV/VIS sensors for long-term sewer monitoring. Water Pract. Technol. 2006, 1, 1. [CrossRef]

8. Yuan, D.H.; He, J.W.; Li, C.W.; Guo, X.J.; Xiong, Y.; Yan, C.L. Insights into the pollutant-removal performance and DOM characteristics of stormwater runoff during grassy-swales treatment. Environ. Technol. 2019, 40, 441-450. [CrossRef]

9. Weishaar, J.L.; Aiken, G.R.; Bergamaschi, B.A.; Fram, M.S.; Fujii, R.; Mopper, K. Evaluation of specific ultraviolet absorbance as an indicator of the chemical composition and reactivity of dissolved organic carbon. Environ. Sci. Technol. 2003, 37, 4702-4708. [CrossRef]

10. He, X.; Xi, B.; Wei, Z.; Guo, X.; Li, M.; An, D.; Liu, H. Spectroscopic characterization of water extractable organic matter during composting of municipal solid waste. Chemosphere 2011, 82, 541-548. [CrossRef]

11. Helms, J.R.; Stubbins, A.; Ritchie, J.D.; Minor, E.C.; Kieber, D.J.; Mopper, K. Absorption spectral slopes and slope ratios as indicators of molecular weight, source, and photobleaching of chromophoric dissolved organic matter. Limnol. Oceanogr. 2008, 53, 559-569. [CrossRef]

12. Irvine, K.; Rossi, M.C.; Vermette, S.; Bakert, J.; Kleinfelder, K. Illicit discharge detection and elimination: Low cost options for source identification and trackdown in stormwater systems. Urban Water J. 2011, 8, 379-395. [CrossRef]

13. Panasiuk, O.; Hedström, A.; Marsalek, J.; Ashley, R.M.; Viklander, M. Contamination of stormwater by wastewater: A review of detection methods. J. Environ. Manag. 2015, 152, 241-250. [CrossRef] [PubMed]

14. Jones, K.P. New lamps for old-Recent progress in UV sources for absorption detectors in liquid. TRAC: Trends Anal. Chem. 2016, 9, 195. [CrossRef]

15. O'Toole, M.; Diamond, D. Absorbance based light emitting diode optical sensors and sensing devices. Sensors 2008, 8, 2453-2479. [CrossRef] [PubMed]

16. Visconti, P.; Primiceri, P.; de Fazio, R.; Ekuakille, A.L. A solar-powered white led-based uv-vis spectrophotometric system managed by pc for air pollution detection in faraway and unfriendly locations. Int. J. Smart Sens. Intell. Syst. 2017, 10, 1. [CrossRef]

17. Piasecki, T.; Breadmore, M.C.; Macka, M. White LEDs as broad spectrum light sources for spectrophotometry: Demonstration in the visible spectrum range in a diode-array spectrophotometric detector. Electrophoresis 2010, 31, 3737-3744. [CrossRef] [PubMed]

18. Kim, J.S.; Kim, A.H.; Oh, H.B.; Goh, B.J.; Lee, E.S.; Kim, J.S.; Jun, J.H. Simple LED spectrophotometer for analysis of color information. Bio-Med. Mater. Eng. 2015, 26, S1773-S1780. [CrossRef]

19. Gómez-Polo, C.; Gómez-Polo, M.; Celemin-Vinuela, A.; De Parga, J.A.M.V. Differences between the human eye and the spectrophotometer in the shade matching of tooth colour. J. Dent. 2014, 42, 742-745. [CrossRef]

20. Francis, F.J. Color measurement and interpretation. In Instrumental Methods for Quality Assurance in Foods; Routledge: Abingdon, UK, 2017; pp. 199-220.

21. Djouadi, A.; Kneur, J.L.; Moultaka, G. SuSpect: A FORTRAN code for the supersymmetric and Higgs particle spectrum in the MSSM. Comput. Phys. Commun. 2007, 176, 426-455. [CrossRef] 
22. Spectra FORTRAN Code. Available online: http://www.physics.sfasu.edu/astro/color/spectra.html (accessed on 24 May 2019).

23. Stephenson, D. A portable diode array spectrophotometer. Appl. Spectrosc. 2016, 70, 874-878. [CrossRef]

24. Jansen-van Vuuren, R.D.; Armin, A.; Pandey, A.K.; Burn, P.L.; Meredith, P. Organic photodiodes: The future of full color detection and image sensing. Adv. Mater. 2016, 28, 4766-4802. [CrossRef] [PubMed]

25. Nie, X.; Ryckeboer, E.; Roelkens, G.; Baets, R. CMOS-compatible broadband co-propagative stationary Fourier transform spectrometer integrated on a silicon nitride photonics platform. Opt. Express 2017, 25, A409-A418. [CrossRef] [PubMed]

26. Čekon, M.; Slávik, R.; Juras, P. Obtainable method of measuring the solar radiant flux based on silicone photodiode element. Appl. Mech. Mater. 2016, 824, 477-484. [CrossRef]

27. Photodiode S12230-1, Sensitive to the Visible and Infrared Spectrum. Available online: http://cort.as/-Hgkl (accessed on 24 May 2019).

28. Photodiode OSD15-E, Sensitive to the Visible Spectrum. Available online: http://cort.as/-Hgkq (accessed on 24 May 2019).

29. Chun, H.; Rajbhandari, S.; Faulkner, G.; Tsonev, D.; Xie, E.; McKendry, J.J.D.; Haas, H. LED based wavelength division multiplexed $10 \mathrm{~Gb} / \mathrm{s}$ visible light communications. J. Lightwave Technol. 2016, 34, 3047-3052. [CrossRef]

30. LED VAOL-5EUV8T4 385 nm Wavelength Peak. Available online: http://cort.as/-Hbwt (accessed on 24 May 2019).

31. Spectrophotometer V-5000 VIS. Available online: http://cort.as/-HglF (accessed on 24 May 2019).

32. Min, Y.K.; Clauberg, B.; Hontelé, B.J. LED Driver Circuit with PWM Output. U.S. Patent 6,586,890, 5 June 2003.

33. Hu, Y.; Jovanovic, M.M. LED driver with self-adaptive drive voltage. IEEE Trans. Power Electron. 2008, 23, 3116-3125. [CrossRef]

34. Dasgupta, P.K.; Eom, I.Y.; Morris, K.J.; Li, J. Light emitting diode-based detectors: Absorbance, fluorescence and spectroelectrochemical measurements in a planar flow-through cell. Anal. Chim. Acta 2003, 500, 337-364. [CrossRef]

35. Li, L.; Wang, Z.; Pei, F.; Wang, X. Improved illumination for vision-based defect inspection of highly reflective metal surface. Chin. Opt. Lett. 2013, 11, 021102.

36. LED C503B-BCN-CW0Y04520-30. 470 nm Wavelength Peak. Available online: http://cort.as/-Hbju (accessed on 24 May 2019).

37. Komiyama, R.; Kageyama, T.; Miura, M.; Miyashita, H.; Lee, S.S. Turbidity Monitoring of Lake Water by Transmittance Measuresment with a Simple Optical Setup. In Proceedings of the 2015 IEEE SENSORS, Busan, Korea, 1-4 November 2015.

38. LED SSL-LX5093UEGC. $500 \mathrm{~nm}$ Wavelength Peak. Available online: http://cort.as/-HdZE (accessed on 24 May 2019).

39. Lüders, K.; Pohl, R.O. Diffraction. In Pohl's Introduction to Physics; Springer: Cham, Switzerland, 2018; pp. 413-442.

40. Stone, M. A Field Guide to Digital Color; AK Peters/CRC Press: New York, NY, USA, 2016.

41. Aydın, C.; Mansour, S.A.; Alahmed, Z.A.; Yakuphanoglu, F. Structural and optical characterization of sol-gel derived boron doped Fe $2 \mathrm{O} 3$ nanostructured films. J Sol-Gel Sci. Technol. 2012, 62, 397-403. [CrossRef]

42. Coutsias, E.A.; Seok, C.; Dill, K.A. Using quaternions to calculate RMSD. J. Comput. Chem. 2004, 25, $1849-1857$. [CrossRef]

(C) 2019 by the authors. Licensee MDPI, Basel, Switzerland. This article is an open access article distributed under the terms and conditions of the Creative Commons Attribution (CC BY) license (http://creativecommons.org/licenses/by/4.0/). 